\title{
TEMPORALIDAD E INTENCIONALIDAD PASIVA EN LOS MANUSCRITOS C
}

Francisco Conde Soto

Universidad de Barcelona

Los manuscritos C, e E. Husserl, constituyen un grupo de manuscritos de investigación redactados entre los años 1929 y 1934 que se extienden a lo largo de unas 600 páginas y que en su mayoría no habían sido publicados hasta el año 2006. Acaban de aparecer en la colección Husserliana Materialien editados por el director del archivo de Colonia Dr. Prof. Dieter Lohmar: Späte Texte über Zeitkonstitution. Die C-Manuskripten, Husserliana Materialien, vol. 8, Springer, 2006. Las cuestiones tratadas por estos manuscritos son muy dispares y aunque supuestamente el eje central lo constituye el análisis de la conciencia de tiempo, lo cierto es que los desarrollos que se alejan de éste tema son numerosos. ' Los manuscritos $\mathrm{C}$ son todavía más fragmentarios que los manuscritos de Bernau, pero en contrapartida la coherencia de los textos es mucho mayor, algo que facilita enormemente su ya de por sí complejo análisis y ordenamiento. La cuestión principal que nos ocupará en este artículo será el intento de realizar una caracterización de un nuevo concepto que viene a centrar el análisis del problema de la conciencia de tiempo: "presente fluyente", "presente primordial" o "presente viviente" (strömende Gegenwart, urtümliche Gegenwart, lebendige Gegenwart). Husserl distingue entre un flujo de conciencia originario absoluto y el plano del tiempo inmanente en el que se muestran las vivencias de esta conciencia al ser objeto de reflexión. Conciencia originaria porque consiste en el mero vivir sus vivencias por parte de la conciencia y absoluta porque no existe

1 Que no esté muy claro cuál sea el tema principal de los manuscritos C lo demuestra por ejemplo que Montavont $(1999,13)$ asegure que antes que de la temporalidad ellos se ocupan de la subjetividad; esta consideración es válida si no se olvida que la subjetividad no es más que cierto movimiento de temporalización continua de sentido. 
ningún plano de conciencia que esté situado por detrás de ella. Frente a esta cabe distinguir la serie en la que vienen a situarse cada una de las vivencias cuando reflexionamos sobre ellas constituye el tiempo inmanente, que coincide con el tiempo objetivo. El uso aquí reiterado del adjetivo "viviente" viene a destacar una novedad en los análisis husserlianos de los manuscritos C: Husserl va a insistir en el carácter dinámico de los procesos de constitución de la conciencia. El presente viviente vendrá a ser identificado con otro concepto que ya había sido introducido en los manuscritos de Bernau (1917/1918): se trata del concepto de un proto-yo o yo que opera "anónimamente", de forma pre-reflexiva y que se autotemporaliza a sí mismo generando aquello que en la reflexión es percibido como la unidad de una vivencia inmanente. Otra de las cuestiones que trataremos en este artículo es el estudio de la reflexión como vía de acceso a este presente viviente será también objeto de estudio pormenorizado. Por último, volverá a tocarse, aunque más parcialmente, la discusión en torno a la intencionalidad pasiva y a los procesos de constitución hilética.

Algunos fragmentos de los manuscritos $\mathrm{C}$ ya han sido editados en los volúmenes XV (partes del 1, 3, 11, 16 y 17) y XXXIV (partes del 2, 3, 7, 16 y 17) de Husserliana. Cuando se cita alguno de estos textos se hará indicando de qué manuscrito se trata y poniendo al lado la página y el volumen en el que se encuentran. El editor del volumen de Husserliana Materialien, Prof. Dr. Dieter Lohmar, nos había permitido consultar una versión prácticamente definitiva de la transcripción de los textos que finalmente han sido editados. Estos textos se citarán indicando el manuscrito y la hoja de la paginación original de los manuscritos de Husserl.

\section{Temporalización absoluta y presente viviente}

En el primero de los manuscritos $\mathrm{C}$, publicado como el texto número 38 del primero de los tres tomos dedicados a la intersubjetividad ( $\mathrm{Hu} \mathrm{XV,} \mathrm{666-}$ -670), Husserl comenzaba hablando de un "protopresente que no es ninguna modalidad temporal" (Hu XV, 667), en el sentido de que esta conciencia no está situada en ningún momento temporal. En cuanto conciencia tempo-constituidora es siempre una pura actualidad situada fuera del tiempo. Este protopresente es la esfera de ser actual más originaria a partir de la cual se generan todos los otros tiempos: el tiempo temporalizado de mi yo, el tiempo temporalizado de los otros yos, el tiempo intersubjetivo, etc. Antes que de un presente estático es preferible hablar de un movimiento de temporalización o síntesis universal, un movimiento de temporalización en el que se genera todo sentido, es decir, toda dación de sentido es el resultado de una constitu- 
ción temporal. ${ }^{1}$ Se trata de cierto absoluto compartido por todos los yos o mónadas, como dice el propio Husserl, descubierto en la reflexión como aquel que constituye la temporalidad mundana de cada mónada. Un presente permaneciente-fluyente (stehend-strömend) en el que el mundo tiene su validez, en el que el todo absoluto de todas las mónadas está siendo temporalizado: estático porque se trata siempre de la misma estructura, inamovible e intemporal; fluyente porque su "contenido", es decir, varían las nuevas daciones que a cada instante llegan. La validez de cualquier sentido tiene sentido dentro de este presente viviente fluyente. La protocorriente del presente viviente ejerce una prototemporalización de la que surge el mundo espacio-temporal. Todos los tiempos, objetos, sentidos se generan, tienen su origen en el protofluir del presente viviente.

Este movimiento de temporalización, corriente absoluta o presente originario constituye la unidad del todo, temporaliza de forma absoluta. Lo absoluto propiamente hablando no es el mundo ni el conjunto de las mónadas sino el movimiento de temporalización, el ahora fluyente-permaneciente "das stehend-strömendes Jetzt" (Hu XV, 670) en el que son constituidos ambos.

De hecho, incluso la consideración de que el presente permaneciente-viviente que yo capto en la reflexión coincide con la temporalización absoluta y primera debe ser evitada, puesto que mi presente viviente es ya un resultado, una ex-crecencia de esta temporalización u origen intemporalizable.

Lo absoluto no es otra cosa que una temporalización absoluta y ya interpretarlo como algo absoluto, que encuentro directamente como mi primitividad permaneciente-fluyente es una temporalización de esto en algo protosiente. De esta forma, [se ve] que el todo absoluto de las mónadas, o sea, la primitividad omnimonádica [surge] sólo a partir de la temporalización (Hu XV, 670). ${ }^{2}$

En los manuscritos C Husserl introducirá el término "vida" para referirse al carácter primordialmente activo de este continuo movimiento de temporalización formado por múltiples temporalizaciones individuales, de cada una de las cuales surge cada una de las vivencias.

Mientras que de los objetos se tiene experiencia e incluso se puede afirmar que los actos de constitución de estos objetos son experimentados, el

\footnotetext{
1 "El mundo perceptivo entero, la multiplicidad abierta de daciones una vez percibidas o perceptibles tiene su, origen' genético en el proceso protoconstitutivo de la presentificación viva“" (Held 1966, 37).

2 "Das Absolute ist nichts anderes als absolute Zeitigung, und schon ihre Auslegung als das Absolute, das ich direkt als meine stehend-strömende Urtümlichkeit vorfinde, ist Zeitigung, dieses zum Urseienden. Und so ist das absolute Monadenall bzw. die allmonadische Urtümlichkeit nur aus Zeitigung" (Hu XV, 670).
} 
yo mismo constituidor, la vida misma que él es, se sitúa fuera de este plano. Se trata de una estructura esencial situada más allá, una corriente de conciencia trascendental que sin mostrarse ella misma en el mundo de la experiencia es la responsable de la genésis del mundo.

El hacer operante es él mismo algo que es, si se exceptúa aquello que gana su validez en cuanto algo que es en él' y que pertenece a aquel conjunto de ser que (en el mejor de los casos) es experimentado, pero que no es la vida de experiencia misma ni el yo experimentado en ella. Todo acto yace en una corriente unitaria de la vida trascendental, en cuanto un momento singular que fluye-que hace fluir. Y esta vida unitaria tiene su estructura esencial, a la que está sometida toda vida singular, entre ella los actos. Todas las preguntas trascendentales, partiendo de aquella acerca del sentido trascendental del mundo, remiten manifiestamente en última instancia a la pregunta acerca de esta estructura esencial, o sea, a este protoser o protoocurrir de la corriente de conciencia concreta viviente y al yo que vive en ella, el yo de todos los actos trascendentales, de las operaciones trascendentales $(\mathrm{C} 2,6 \mathrm{~b}){ }^{1}$

El presente viviente es, por lo tanto, cierta estructura anónima - anónima por prerreflexiva, pero en cada caso la mía propia - que opera, trabaja, constituye, temporaliza de forma continua.

Es importante insistir en el carácter no temporal de la noción de presente viviente. La conciencia, el yo, sería mejor hablar simplemente del movimiento de presentación viviente de la conciencia, no se encuentra en el presente. Se trata de un presente fluyente en el sentido de que los contenidos dados varían de forma continua, pero lo importante es advertir que no se trata de un presente situado dentro de una cadena de pasado, presente y futuro. El presente viviente no es sucedido por un presente futuro ni deja atrás un presente pasado, sino que a nivel de la conciencia sólo se puede hablar de un presente "actual" que está donando validez a aquellos objetos que en sentido convencional-inmanente son presentes, pasados y futuros. Ante todo es necesario apreciar que no se trata de ninguna serie de cortes o fases que se sitúen y sucedan en la línea del tiempo. El presente viviente no se extiende a

' „Das leistende Tun ist selbst seiende, abgesehen von dem, was ,darin' als seiend zur Geltung kommt und demjenigen Seinszusammehang angehört, der (bestenfalls) erfahren ist, aber nicht das erfahrende Leben selbst ist und das darin erfahrende Ich selbst ist. Jeder Akt liegt im einheitlichen Strom des transzendentalen Lebens, darin ein strömend-verströmendes Sondermoment. Und dieses einheilichte Leben hat seine Wesensstruktur, an die alles Sonderleben, darunter die Akte, gebunden ist. Alle transzendentalen Fragen, auslaufend von der nach dem transzendentalen Sinn der Welt, führen offenbar letzlich zurück auf die Frage nach dieser Wesensstruktur bzw. auf dieses Ursein oder Urgeschehen des konkret lebendigen transzendentalen Bewusstseinstromes und das in ihm erlebende Ich, das Ich aller transzendentalen Akte, aller transzendentalen Leistungen" $(C 2,6 b)$. 
lo largo de determinado tiempo inmanente, no consiste en ningún tipo de sucesión, sino que se trata del corte actual viviente-fluyente en el que a cada instante y continuamente se produce la dación de un mundo. El presente viviente fluyente es un flujo únicamente por analogía con el tiempo inmanente-objetivo, pero no porque él mismo consista en algún fluir. La sucesión temporal de pasado, presente y futuro es el resultado de una cierta objetivación realizada a partir de las valideces que originariamente se dan en el presente viviente. La perduración de estas valideces es la que permite que se constituya el pasado: éste consiste en el hecho de que aquello dado en un presente viviente sigue teniendo determinada validez en la actualidad. Los momentos de pasado, presente y futuro son distinciones que el yo trascendental-fenomenologizante, es decir, el yo que efectúa la reducción, puede realizar sobre el horizonte total temporalmente indiferenciado que es en realidad el presente viviente $(\mathrm{C} 7 \mathrm{a}, 6)$.

El carácter atemporal del presente viviente se muestra en su carencia de principio o fin $(\mathrm{C} 2,24 \mathrm{~b})$. Husserl se refiere al presente viviente como si este fuese una "prototransformación" (Urwandlung) (C3, 15a) responsable del origen del tiempo sin estar situada en ningún tiempo. Por así decir, la conciencia sólo "conoce" presente, vive encerrada en esta estructura que sin ser temporal constituye tiempo, que sin ser ella misma ninguna presencia es la responsable de la presencia de toda validez, de todo sentido.

Puesto que su ser propio en cuanto ser trascendental tal y como es en su protoforma no es ser un presente entendido en sentido normal (incluso en sentido ampliado) en cuanto un elemento intermedio que permanece fluyendo entre un pasado y un futuro cofluyentes. No obstante, el término es inevitable debido a razones inmediatamente comprensibles (Hu XXXIV, 187; C3). ${ }^{1}$

Por lo tanto, cuando se habla de un único presente viviente presentado es en la medida en que se lo considera cierto corte abstracto hecho en el continuo real de los presentes vivientes. Se trata de un "puro presente", pero no en el sentido de un momento del tiempo absolutamente presente, sino en el sentido de que es la forma o estructura por la que "pasa" todo objeto o sentido que se manifieste. Con propiedad ni siquiera se puede afirmar que mi presente viviente fluyente sea el mío en contraste con el de los otros sujetos: esto sólo se puede predicar de mi presente inmanente, de la corriente inmanente de vivencias, o del presente mundano en el que es mi ser humano real y los otros seres humanos. Este presente mundano es algo que cobra valor,

1 „Denn ihr eigenes Sein als transzendentales Sein in der Urgestalt ist nicht etwa in einem normalen (obschon erweiterten) Sinn eine Gegenwart als strömend verharrendes Zwischenstück für eine mitströmende Vergangenheit und Zukunft. Gleichwohl ist das Wort aus bald verständlichen Gründen unvermeidlich“ (Hu XXXIV, 187; C3). 
que tiene validez (geltenden), gracias a mi presente viviente y no al contrario. El presente viviente no se reduce a ser la esfera en la que cobran sentido y validez las valideces que temporalmente son presentes, sino también aquella en la que se conservan algunas de las valideces pasadas y en la que se pre-apunta a posibles valideces futuras. Se trata de un mero flujo, de un mero fluir dinámico donde no es posible localizar ninguna sucesión o corriente en sentido habitual. "Última concreción", "vida noética absoluta concreta" (Hu $\mathrm{XV}, 106$; $\mathrm{C} 3$ ), recordando que el término noesis se refiere aquí a los procesos constitutivos-activos y no a las noesis en cuanto actos inmanentes captados en la reflexión.

Husserl distingue diferentes estructuras o niveles vinculados al presente viviente: 1) el nivel de la asociación o síntesis pasiva temporal, 2) el nivel de los actos intencionales y 3 ) el nivel del yo y el mundo en cuanto constituidos, en cuanto correlatos de los actos $(\mathrm{C} 3,25 \mathrm{a})$. Todos ellos se ponen en juego en virtud del movimiento del presente viviente. El nivel de la asociación pasiva contiene las síntesis de la conciencia interna constituidora de tiempo que se establecen entre protoimpresiones, retenciones y protenciones mediante las que se vive internamente la unidad de cada vivencia y el peculiar "flujo" que ella misma es. ${ }^{1}$ Esta temporalización absoluta previa a las temporalizaciones individuales es una temporalización pasiva. Las constituciones o temporalizaciones de nivel superior de las que surgen los objetos sensibles son activas, en el sentido de que las precede un dirigirse, una toma de interés y una actividad dotada de algún fin por parte del sujeto. A esta actividad de cada sujeto la precede algún tipo de presupuesto o condición de su posibilidad: una temporalización absoluta originaria, el "faktum" mismo que es el presente vivo, las operaciones en el interior del cual son posibles los diferentes procesos constitutivos. El siguiente nivel, sería el nivel de los actos intencionales, es decir, el tiempo inmanente en que se suceden las vivencias (parte de las cuales pueden ser no intencionales), y finalmente, el tercer nivel, sería el nivel de los objetos intencionados por los actos intencionales. Lo interesante no es la estructuración, ya conocida, de los niveles de constitución, sino el hecho de que Husserl insiste en que estos tres niveles están operando como incluidos dentro del presente viviente. Es decir, el presente viviente al mismo tiempo que es asociación pasiva, opera intencionalmente y constituye los objetos mundanos.

Si se ha insistido en su carácter no temporal, también hay que insistir en que el presente viviente no consiste en el corte perceptivo presente. No es aquello que se percibe del mundo en el momento presente. El presente vi-

${ }^{1}$ Beils $(1987,214)$ recuerda que Ingarden habla de una cierta "trascendencia estructural atenuada" refiriéndose a la relación entre la "conciencia interna" y sus objetos (Der Streit um die Existenz der Welt, Tomo II/1, s. 224/25), en cuanto ellos serían el resultado de cierta génesis temporal "previa". 
viente no es el campo de la percepción actual o campo de percepción primario, sino que esto último es aquello que él da. Entre los dos sentidos diferentes que tiene el término, por una parte, el presente constituido en cuanto el corte perceptivo, o mejor dicho, el sentido total constituido en un corte del presente, por otra, la subjetividad constituidora en cuanto el movimiento operante constituidor o, como el mismo Husserl dice, en cuanto la "viveza protobrotante" (urquellende Lebendigkeit) $(\mathrm{C} 3,45 \mathrm{~b})$, es el segundo el que debe prevalecer. El presente viviente no es un mero flujo de experiencias. Una vez que se efectúa la reducción sobre el flujo inmanente de conciencia lo que queda no puede esțar dotado de una temporalidad, no puede ser algo donde ocurra una sucesión temporal, no puede ser algo donde se sucedan unos elementos a otros. El presente viviente se sitúa en un flujo trascendental dotado de un pre-ser que fluye en un pre-tiempo y que origina una pre-temporalización. Mientras que el modo temporal de la vida primaria de la conciencia trascendental es presente viviente (pre-ser, pre-tiempo), el modo de ser de la corriente de vivencias es el tiempo objetivo inmanente. Por lo tanto, es también erróneo interrogarse acerca de cómo se establece la relación entre diferentes procesos de dación o temporalización que tienen lugar en distintos presentes vivientes. Que está fuera del tiempo implica que en él ocurre un proceso de síntesis entre protoimpresiones, retenciones y protenciones fuera del tiempo, que sólo gracias a él hay tiempo sin que él mismo esté en el tiempo. En el presente viviente tiene su "presencia" un determinado campo formado no sólo por aquello temporalmente presente, un determinado campo perceptivo, sino también por todo aquello pasado o futuro cuya validez está operando actualmente. No se reduce a ser un único presente absoluto o primario, sino que en él pueden tener cabida daciones pasadas en el modo del recuerdo o de la retención y daciones futuras en el modo de la expectativa o de la protención. Por ejemplo: en él tienen validez también los objetos pasados que pueden estar siendo recordados.

Propiamente hablando el presente viviente es pues un prototiempo, protonoesis o constituir fluyente, una corriente de vida (Lebensstrom), un flujo que es ser-fluyendo, el "movimiento" de fluir-constituir que es el presente viviente por sí mismo. Pero este presente viviente se trasciende a sí mismo y constituye el tiempo inmanente-objetivo, el tiempo de los actos intencionales y de los objetos intencionales que les corresponden. El tiempo inmanente es constituido como aquel tiempo en el que es situado el ser individual originario. Se trata ya de una primera "trascendencia" con respecto al presente fluyente de la presencia originaria concreta, de algo que es resultado del movimiento de este último.

En el transcurrir protofenomenal de la protopresencia esta vida misma se trasciende, constituye el tiempo inmanente, la corriente de vivencias con su pasado 
y su futuro y una esfera ya terminada, pasada de ser permaneciente-idéntico que se enriquece continuamente (Hu XXXIV, 171; C5). ${ }^{1}$

El "movimiento" del presente viviente constituye así un tiempo de los objetos temporales y un tiempo (captado como inmanente) de las vivencias. Un sonido se constituye en su fluir como una unidad temporal constituida.

Un matiz especialmente relevante con respecto a exposiciones anteriores de la fenomenología del tiempo (las lecciones de 1904/05 recogidas en el volumen $\mathrm{Hu}$ X o los manuscritos de Bernau 1917/18 del volumen $\mathrm{Hu}$ XXXIII) lo constituye el hecho de que el término "impresión originaria" es usado en muy pocas ocasiones. Quizás Husserl intenta así desprenderse de la idea de que haya daciones singulares de un punto-ahora, insistiendo en mostrar que el presente viviente se refiere siempre a la dación de un contenido concreto que se da como un contenido que dura. En términos de épocas anteriores se puede afirmar que el presente viviente es una fase de la corriente originaria de conciencia, por lo tanto, en ella no se encuentra solamente una protoimpresión, sino también un continuo retencional y un continuo protencional. El contenido que se da no es sólo un contenido protoimpresional, sino un resultado de esos tres momentos de la conciencia. El concepto de un presente entendido como impresión momentánea dadora de un punto temporal es una abstracción que se puede comprender una vez establecida la diferencia esencial entre la conciencia absoluta - presente viviente y el plano inmanente - objetivo de los objetos temporales. Cuando se hable de impresión a partir de ahora se hará en referencia a la dación de un concreto que se constituye como algo que al mismo tiempo "deviene y es" (Werdend-Seiendes $(\mathrm{C}, 76 \mathrm{a})$ ) a lo largo de una corriente originaria. Retención y protención no son pasado o futuro en relación a la impresión primaria, sino que están "juntas" con ella en el interior del presente viviente antes de ser nada en el tiempo. Dicho en otros términos: no percibimos los contenidos dados por las impresiones originarias, sino concretos resultado de una dación en la que opera todo el presente viviente. El presente concreto viviente es un concepto opuesto a la idea de una fase-fuente (Quellphase) impresional originaria. La temporalización de la conciencia consiste en la constitución de un presente perceptivo concreto de unidades que duran, y no sólo de puntos de estas unidades.

1 „Im urphänomenalen Strömen des Urpräsenz transzendiert sich dieses Leben selbst, es konstituiert die immanente Zeit, den Erlebnisstrom mit seiner Vergangenheit und Zukunft und eine erledigte seiende, vergangenheitliche Sphäre verharrend-identischen Seins, die sich stetig bereichert" (Hu XXXIV, 171). 


\section{La reducción fenomenológica al presente viviente anónimo. La re- flexión}

En un primer momento Husserl no quiere plantearse cómo es posible que un acto de reflexión sea capaz de captar las operaciones de la proto-conciencia que previamente a la reflexión transcurrían de forma anónima. Simplemente se contenta con afirmar que es suficiente con advertir la existencia fáctica de reflexiones.

Yo, ahora, el que reflexiona, tengo en esta vida objeto de conciencia originalmente, en esta vida inmanente también naturalmente el hacer reflexionante, en el que se tiene conciencia temáticamente de todo lo así constatado, incluido también a su vez este mismo hacer reflexionante. Cómo sucede y cómo puede suceder esto, este retrorreferirse a sí mismo y este retrorreferirse a su propio retrorreferirse es naturalmente un problema - pero de entrada no es el que nos ocupa. Es suficiente con constatar que evidentemente se produce $(\mathrm{C} 7,42 \mathrm{a}){ }^{1}{ }^{1}$

Sin embargo, en textos posteriores surge un intento de explicación para el hecho de que a partir de determinado momento el yo comienza a reflexionar sobre su propia corriente de vivencias. Hasta ahora se ha hablado de un presente viviente que precede a todos las constituciones de sentido, pero no se ha tratado el tema de cómo es posible acceder a él, es decir, qué dación fenomenológica se tiene de tal presente. En Ideas I la reflexión era entendida al modo de una percepción inmanente, es decir, como un volverse hacia las propias vivencias (erleben) de la conciencia interna y captarlas como vivencias (Erlebnisse) situadas en el tiempo inmanente. La reflexión capta las operaciones del presente viviente como vivencias inmanentes. El problema que se plantea es la cuestión acerca de qué motivos existen para hablar de algo situado más allá de ellas, por así decir, previo a ellas. La reflexión se produce siempre al modo de un retornar sobre algo previo. En cualquier momento es posible que el yo ejerza una reflexión sobre sus actividades como resultado de la cual encuentra sus propias actividades, aunque al modo de vivencias inmanentes: la cuestión es aclarar cómo se alcanza la idea de que estas habían sido ya generadas en un presente viviente. La reflexión detecta en esta operación que hay algo que no sólo la antecede, sino algo que queda más allá de lo que puede traer a dación adecuada: el acto mismo en su operar, la vivencia en su ser vivida. Se "supone" entonces que a la vivencia

1 „Ich jetzt, der Besinnende, habe in diesem original bewussten, immanenten Leben natürlich auch das besinnliche Tun, worin also alles soeben Konstatierte thematisch bewusst wird, und dazu rechnet dann auch selbst wieder dieses besinnliche Tun selbst. Wie das geschieht und geschehen kann, dieses < Sich>-auf-sich-selbst-Zurückbeziehen und <das> Auf-das-Rückbeziehen-selbst-sich-rückbeziehende-Tun ist natürlich ein Problem - zunächst aber ist es noch nicht an der Reihe. Genug, es geschieht offenbar" (C7, 42a). 
tal y como es captada inmanentemente en la reflexión tiene que antecederla un operar constitutivo de sentido que ocurre primeramente de forma anónima, de forma "no comprendida" (Hu XV, 299). Incluso cuando la reflexión que está siendo efectuada reflexiona sobre sí misma esta "estructura" permanece más allá, cerrada sobre sí misma. Se descubre una dimensión anónima constituidora y operante que precede a toda reflexión: es necesario presuponer un tener-vivencia previo sobre el que se realiza la reflexión, una vida operante y un yo anteriores que permanecen anónimos. En oposición a esta vida de la conciencia se encuentra la experiencia como formada por una serie de unidades construidas en virtud de una temporalización de una multiplicidad previa: "El yo no consiste originariamente en experiencia - en el sentido de apercepciones asociativas en las que se constituyen unidades a partir de multiplicidades relacionadas - sino en vida (es lo que es, no sólo para el yo, sino el yo mismo) $(\mathrm{C} 17,4){ }^{1}$

En el manuscrito C2 y en el C3 Husserl se interroga acerca de la ejecución de la reducción fenomenológica como vía de acceso al presente viviente. A través de la reducción en la que se ponen fuera de juego la apercepción natural de mí mismo y del mundo que me rodea se descubre el campo de la vida trascendental de conciencia: una corriente de vivencias noéticas situadas en el tiempo inmanente. Pero el plano de conciencia inmanente ganado tras esta primera reducción es todavía algún tipo de "producto constituido" [konstituiertes Gebilde $(\mathrm{C} 2,8 \mathrm{~b})$ en relación a una proto-"inmanencia" anterior. Hay una estructura "eterna" previa, un "nunc stans" continuo.

El concepto de "nunc stans" es un concepto escolástico empleado para referirse a la eternidad. Se trata del ahora que permanece, en cuanto hacedor de la eternidad, una duración sin comienzo ni fin que en ella misma sería un punto inextenso de tiempo que es "siempre ahora". Contrastraría con el "nunc fluens" o ahora que fluye, que sería hacedor del tiempo. Schopenhauer dice al respecto del tema: "Sólo la incomprensión de los muy incapaces no ha sabido explicarse el concepto de la eternidad de otro modo que el de un tiempo infinito. Esto obligaba a los escolásticos a afirmar. «Aeternitas non est temporis sine fine sucessio, sed nunc stans», pues ya lo había dicho Platón en el Timeo, y Plotino lo repite" $(1989,264)$. La eternidad es interpretada por algunos pensadores medievales, Boecio entre ellos, como un tiempo in-finito, es decir, sin comienzo ni fin, pero no una duración, no 'algo sempiterno'; sino el propio tiempo que dura (Coomaraswamy 1999, 128). La expresión es empleada también por algunos místicos latinos para referirse a

1 „Das Ich ist ursprünglich nicht aus Erfahrung - im Sinne von assoziativer Apperzeption, in der sich Einheiten von Mannigfaltigkeiten des Zusammenhanges konstituieren - sondern aus Leben (es ist, was es ist, nicht fü r das Ich, sondern selbst das.Ich)“ (C 17 IV, 4). Brand juega con esta terminología y afirma que la reflexión no podría captar esta vida pre-reflexiva, puesto que ella se dirige siempre a una experiencia (Brand 1955, 73). 
la sensación de un "ahora inmóvil" arrebatado al tiempo en él que se puede contemplar lo divino. Eigler habla de una secularización del concepto de nunc stans en Husserl:

Así, nos encontramos en Husserl el pensamiento de la eternidad y el tiempo de nuevo, aunque como la 'secularización' más externa del pensamiento medieval del ser de dios como nunc stans. La subjetividad trascendental es un nunc stans, que permite la presencia del tiempo, siendo él mismo atemporal. Aquí sólo resta del pensamiento de la eternidad, en la medida en que la subjetividad trascendental es, la noción de la presencia constante (Eigler 1961, 115).

El término ya aparecía en las Meditaciones Cartesianas. Allí Husserl hablaba de la conciencia constituidora de tiempo como la forma fundamental sobre la que se asientan todas las otras síntesis de la conciencia. El correlato de esta conciencia constituidora es la temporalidad inmanente, es decir, el ordenamiento temporal en el que son percibidas todas las vivencias del yo cuando se reflexiona sobre ellas (Hu I, 81). La conciencia efectúa una cierta autoconstitución trascendental a través de la cual constituye el ordenamiento temporal de sus propias vivencias (Hu I, 133). El tiempo inmanente no es más que aquel en el que se van ordenando las diferentes vivencias que atraviesan por la forma unitaria del transcurrir de la conciencia, por el 'nunc stans' de la conciencia (Hu I, 109). Es decir, la estructura del presente viviente está caracterizada por ser un nunc stans-fluens, por ser un continuo "retirarse" que deja paso a un nuevo presente viviente.

Más allá de la vida o flujo temporal inmanente se sitúa por lo tanto un cierto operar activo del que ella misma es el resultado. En cuanto que "producto" o constructo ella misma debe ser sometida a una nueva reducción tras la que se descubre una vida trascendental más primaria. Tras la corriente de conciencia en cuanto corriente formada por una serie de actos constitutivos a los que corresponde un yo trascendental se encuentra un cierto presente viviente, una estructura o forma originaria (Urgestalt) $(\mathrm{C} 2,10 \mathrm{a})$ situada todavía más allá del yo que opera como correlato del mundo.

Una operación intencional fundada es, sin embargo, la vida de conciencia universal, o sea, el yo-conciencia, que atraviesa el tiempo trascendental-inmanente en cuanto, corriente de conciencia'. De entrada necesitamos ingenuamente presuponer este yo como el sujeto absoluto de la experiencia universal trascendental en la que se tiene experiencia del mundo (y dentro de ella el ser humano y la experiencia de todo lo humano). Pero este yo trascendental y esta vida trascendental que le es propia es ya una formación construida y en cuanto tal debe ser puesta entre paréntesis. Esto quiere decir que mediante esta reducción llegamos finalmente a un proto-yo traścendental y a una protovida trascendental en la que se temporaliza, en la que gana ser en una temporalidad 
inmanente trascendental todo yo trascendental concreto (con la vida trascendental, en la que él es activo y afectado, en la que él es operante a su manera) (Hu XXXIV, 300; C2). ${ }^{1}$

Todo aquello que es captado como presente en la reflexión remite todavía a una operación anterior de la que surge, de la que es "fenómeno" ("Phänomen" (C, 10a)), en el sentido de que se trata de una aparición fundamentada sobre este nivel anterior. La única novedad la constituye la introducción del yo en cuanto otra denominación para esa peculiar conciencia interna, es decir, el reconocimiento de que en cada caso el vivir y el tener conciencia son el mío propio. En todo caso, la reducción trascendental como vía de acceso al presente viviente no se detiene en el descubrimiento de que existe un yo que tiene como correlato el mundo, sino que es preciso advertir que este yo es un yo operante, un yo trascendental que antes de que se dirija la reflexión sobre él se encuentra ya operando de forma no tematizada y anónima en diferentes actos. Con anterioridad a los actos espontáneos de captación del yo el presente viviente operaba y opera fundando continuamente sentido.

El análisis de la estructura del presente primordial (el fluir viviente permaneciente) nos conduce a la estructura del yo y al subnivel continuo del fluir no-egoico que lo funda, que siguiendo una pregunta consecuente acerca de aquello que también hace posible y presupone la actividad sedimentada remite a lo pre-egoico radical ( $\mathrm{Hu} \mathrm{XV}, 598$; no son los manuscritos C). ${ }^{2}$

Cuando se reflexiona sobre él, el presente protooriginal es captado como una fase presente de la vida de conciencia transcendental. El acceso reflexivo al presente proto-originario no es un acceso directo que lo capte en

${ }^{1}$ „Eine fundierte intentionale Leistung ist aber das universale Bewusstseinsleben bzw. Bewusstseins-Ich, das durch eine transzendental-immanente Zeit sich als ,Bewusstseinstrom' hindurchzieht. Zunächst sind wir naiv genötigt, dieses Ich als das absolute Subjekt der universalen transzendentalen Erfahrung, in der die Welt (und darin der Mensch und das alle Menschliche Erfahren) erfahren ist, vorauszusetzen. Aber dieses transzendentale Ich und dieses ihm eigene transzendentale Leben ist schon ein konstituiertes Gebilde und als das einzuklammern. Das besagt, wir kommen durch diese Reduktion letzlich auf ein transzendentales Ur-Ich und ein transzendentales Urleben, in dem jenes transzendentale konkrete Ich (mit dem transzendentalen Leben, in dem es aktives und affiziertes, in dem es überhaupt in seiner Weise leistendes ist) gezeitigt wird, Sein gewinnt in einer immanenten transzendentalen Zeitlichkeit“" (Hu XXXIV, 300; C2).

„Die Strukturanalyse der urtümlichen Gegenwart (das stehend lebendige Strömen) führt uns auf die Ichstruktur und die sie fundierende ständige Unterschichte des ichlosen Strömens, das durch eine konsequente Rückfrage auf das, was auch die sedimentierte Aktivität möglich macht und vorausetzt, auf das radikal Vor-ichliche zurückleitet“ (Hu XV, 598; no son los manuscritos C). 
su actividad tal y como esta transcurre. Antes de la reflexión se encuentra ahí como una especie de para-sí-mismo perfecto y anónimo que opera continuamente. La reducción transcendental descubre como estructura fundamental de la conciencia, que antes era una mera concreción o facticidad "muda" todavía sin interpretar o analizar, la estructura del transcurrir:

Volcado sobre mí en cuanto yo trascendental y operar trascendental, en cuanto vida trascendental debo realizar sobre esta misma una reducción trascendental en la que pongo entre paréntesis todas las apercepciones que me son ingenuamente impuestas y que son ya ellas mismas operaciones fundadas. Una operación fundada intencional lo es ya la vida de conciencia universal, o sea, el yo de la conciencia que atraviesa un tiempo trascendental-inmanente en cuanto 'corriente de conciencia' (C2, 8a).

Si observamos esta vida trascendental misma, este ego trascendental, o me observo pre-colocándome como debo en cuanto el yo de todos mis prejuicios, de todo lo que es para mí, es decir, en cuanto protocondición de su sentido de ser, entonces me encuentro en cuanto presente fluyente $(\mathrm{C} 3,10)^{2}$

El propio Husserl es consciente de lo problemático que se hace determinar cuál es el mecanismo a través del que es posible justificar la defensa de la existencia de un proto-yo. La única vía de acceso a la vida trascendental es la reflexión y todo aquello que se aparece en la reflexión lo hace al modo de un objeto. Parece entonces que resulta problemático afirmar que hay algo previo, más originario y anterior a la percepción que efectúa la reflexión. Toda reflexión consiste en un presentar cuyos objetos se aparecen precisamente como algo presentado estático. Así, el yo se aparece en la reflexión siempre como algo objetivado, temporalizado: sea en el modo de la temporalidad del mundo objetivo-externo o en el modo de la temporalidad inmanente, que coinciden. La reflexión fenomenológica más radical sólo puede captar el yo como presente, pero no como presentador, no "en el medio" de su presentación. Husserl afirmaba ya en 1904/05 que el flujo absoluto de multiplicidades a partir de las que se forman como unidades todas las vivencias podría ser captado a través de una cierta "mirada" o "en una re-

1 "[A]uf mich als transzendentales Ich und transzendentales Leisten, also transzendentales Leben zurückgeworfen muss ich an diesem selbst transzendentale Reduktion üben, nämlich alle mir naiv auferlegten Apperzeptionen einklammern, die selbst schon fundierte Leistungen sind. Eine fundierte intentionale Leistung ist aber das universale Bewusstseinsleben bzw. Bewusstseins-ich, das durch eine transzendental-immanente Zeit sich als 'Bewusstseinsstrom' hindurchzieht" (C2, 8a).

2 "Betrachten wir dieses transzendentale Leben selbst, dieses transzendentale Ego, oder betrachte ich mich, als wie ich allen meinen Vorurteilen, allem für-mich-Seienden, voranzusetzen bin, eben als Urbedingung für ihren Seinssinn, so finde ich mich als strömende Gegenwart" $(\mathrm{C} 3,10)$. 
flexión que lo coge al vuelo" (in einer Reflexion erhascht werden) (Hu X, 290) en el medio de su actividad; es decir, la reflexión no puede "pescar" (erhaschen) al yo en el medio de su actividad.

¿Cuáles son las condiciones que le permiten al yo ocuparse de sí mismo y no del mundo presentificado, dirigirse reflexivamente a sí mismo en una auto-presentificación reflexiva? Algunos autores proponen que antes de la reflexión el yo tendría que estar notándose a sí mismo de alguna forma: "pre-forma inexpresable del auto-advertirse reflexivo". (Unausdrücklichen Vorform der reflexiven Selbstgewahrung) (Held, 1966, 82). Según Held, Husserl afirma en algún pasaje que este ser-para-sí del yo se construye en el presente fluyente mismo al modo de un proceso pasivo primario anterior a la reflexión, de una presentificación sintética de la transición que el yo mismo es. La reflexión viene posteriormente a recorrer esta estructura. ${ }^{1}$

La cuestión es ahora precisar en virtud de qué estructura es posible que en determinado momento el yo se gire sobre sí mismo y comience a reflexionar. Formulada en términos de afecciones originarias equivale a la interrogación siguiente: “¿Cómo surge una proto-afección en la que el yo anónimo puede ser afectado por él mismo y por otros yoes?". ${ }^{2}$ Es decir, ¿cómo es posible que el mero operar del proto-yo deje de realizarse de forma anónima y se convierta en objeto del proto-yo que reflexiona? Ante una afección proveniente de una unidad hilética externa el yo desarrolla una acción dirigida a esta unidad. Lo mismo tendría que ser supuesto en el caso de cada una de las ejecuciones sobre las que se inicia un proceso de reflexión. Husserl afirma que la posibilidad de la reflexión presupone una cierta auto-afección continua, requisito necesario si se quiere explicar como la reflexión del yo acerca de sí mismo es una posibilidad continua siempre abierta. No se trata de que el yo reflexione constantemente acerca de sí mismo, sino de que lo puede hacer en virtud de que hay una determinada autoafección ${ }^{3}$ pre-reflexiva produciéndose en todo momento. Esta

\footnotetext{
${ }^{1} \mathrm{Al}$ respecto es interesante la reflexión de Depraz: "Esta alternativa revela la distancia que separa la obra de G. Brand de aquella de K. Held. Mientras que para el primero, la temporalidad originaria se manifiesta precisamente en la estructura reflexiva del yo, para el segundo, el anonimato del yo operante va más allá del acto reflexivo siempre temático" (Depraz 1994, 460).

2 „Wie entspringt eine Uraffektion, in der das anon<yme> Ich von sich selbst und von anderen Ich affiziert werden kann?" (C10, 49b).

3 "Esta conciencia interna que acompaña la realización de todos los actos intencionales de un mismo sujeto, vive estos actos o 'vivencias' intencionales del interior - desde su primera emergencia, durante toda su duración y hasta el momento de su desvanecimiento - a través de lo que Husserl llama 'impresiones originarias' y a través de su comitiva de 'retenciones' y 'protenciones'. Esta conciencia interna es una conciencia impresional que merece el nombre de 'auto-afección' de la conciencia por ella misma" (Bernet 2004, 12). "Ya la primera relación a sí, es decir, la auto-afección carnal implica una separación, una distancia: el sentirse a sí mismo exige ya una distancia temporal, aquella de la impresión originaria
} 
autoafección implica que el presente viviente, en cuanto una unidad de permanecer y fluir, estática-dinámica, se encuentra trascendiéndose a sí mismo dentro de sí mismo, se autoaparece a sí mismo como un presente viviente-fluyente. Cuando se reflexiona se hace manifiesta esta estructura operante, dinámica, activa, que ya anteriormente se estaba "manifestando" a sí misma. La autoafección permite que en un segundo momento el proto-yo sea captado bajo la forma de un polo activo que es correlato de una serie de vivencias inmanentes.

Idealmente puede concebirse un proto-yo cerrado en sí mismo y que no saliese de sí mismo, que constase simplemente de un auto-aparecerse que no necesitase de ningún captarse como flujo inmanente. Se trataría de una conciencia caracterizada por un fluir anónimo del que no se podría jamás tener ningún tipo de "noticia". La cuestión es que el proto-yo se "escinde" de alguna forma, hay algo que rompe la relación perfectamente circular a sí mismo en la que podría encontrarse.

No se trata tan sólo de que en virtud de la afección hilética se produzca una especie de escisión en la vida prototrascendental que hace que esta deje de ser anónima y entre en el tiempo inmanente. Cuando somos afectados por una unidad hilética se aparecen simultáneamente la afección, que origina una determinada vivencia, y el yo afectado correlato de esta como elementos situados en el tiempo inmanente. Pero el proto-yo en sí mismo deber haber efectuado ya previamente un salir de sí que Held, por ejemplo, califica como una "auto-comunalización en el interior del yo" (Held 1966, XI).

Uno de los problemas que afecta a nuestro atender al planteamiento de Husserl es la justificación de por qué la atención se dirige en ocasiones a esta autoafección y en otras no. Parece que además de la autoafección es necesario otro elemento. Si se tratase tan solo de un afectarse a sí mismo el yo estaría continuamente reflexionando sobre sus propias vivencias, no habría ningún tipo de operar anónimo. Si el autoafectarse recibe en cierta ocasión un plus por el que pasa a convertirse en objeto de atención reflexiva, entonces el problema sigue sin resolver, en cuanto que hay que averiguar en qué consiste este plus. $^{2}$

transcurrida. La auto-afección misma es ya en este sentido una primera forma reflexiva, una reflexión viva por así decir a punto de nacer. Es en efecto en tanto que afectado por él mismo como el yo tiene la facultad de ser presente a sí mismo en cada momento mediante una escisión originaria operante que él es de forma anónima y el yo objetivado, escisión que es al mismo tiempo identificación del uno al otro" (Montavont 1999, 132).

1 „Selbstvergemeinschaftung im Innern des Ich“ (Held 1966, XI).

2 La respuesta era en Ideas $I$ que el acto de reflexión es un acto de libertad perfecto. Por ejemplo, al respecto de la reducción: "El intento de duda universal pertenece al reino de nuestra perfecta libertad" (Hu III, 64): "Esta transformación es cosa de nuestra perfecta libertad [...] (Hu III, 65). "Yo hago esto, según mi completa libertad [...] (Hu I, 67). 
En todo caso, la tendencia general de la caracterización que Husserl hace en los manuscritos $\mathrm{C}$ del yo operante o proto-yo no apunta tan claramente a la suposición de una estructura de auto-afección de este tipo. En todo caso, la reflexión establecida sobre dicha estructura no sería nunca una percepción inmanente, sino cierto percatarse de sí mismo a posteriori ("nachgewahren") (Held 1966, 94) diferente de un acto reflexivo en el sentido fenomenológico del término. Si algo evidente hay que constatar es que el yo operante resulta ser una esfera primaria, pre-reflexiva y pre-temporal de la que no es posible ofrecer ninguna caracterización positiva. De ella sólo se puede afirmar legítimamente que se trata de una esfera pre-algo: pre-inmanente, pre-temporal, pre-reflexiva, pre-mundana... Curiosamente la posibilidad de realizar cualquier afirmación acerca de ella debe ser negada si se quiere describir con precisión lo que ella es. El fluir primitivo es algo de lo que no se puede tener experiencia (fenomenológica) y acerca de lo que no se puede decir nada: si es objetivado, comprendido entonces como algo temporal, pierde entonces su carácter genuino de ser un presente viviente. Parece que en cierto sentido la exigencia husserliana de que la fenomenología debe basarse en todo momento en daciones claras encuentra su límite en el hecho de que uno de los conceptos operativos - el de presente viviente - no puede ser captado de tal forma, sino que se trata de una "dación de un tipo totalmente peculiar" (Held 1966, 75). ${ }^{1}$

La protocorriente sólo se podría dar como tal si pudiese ser captada antes y fuera de la temporalidad en la que se transforma cuando es captada intuitiva-reflexivamente. Ya en Ideas II se afirmaba:

A la esencia del autorecuerdo pertenece claramente el tener conciencia del yo puro autorrecordado como algo pasado, pero también que sea posible un cambio en la dirección de la mirada mediante el que el yo puro se capta a sí mismo en cuanto yo puro del acto de rememoración, por lo tanto, en cuanto presente actual autopercibido (Hu IV, 101). Yo soy también un objeto para mí sólo en la medida en que tengo 'autoconciencia', incluso cuando no reflexiono. Si no la tuviese, no podría tampoco reflexionar (Hu IV, 318$){ }^{2}$

1 Pese a ello, y también según Held, ciertos autores como Seebohm irían demasiado lejos afirmando que la pregunta por aquello anterior al yo correlato de las vivencias inmanentes es una mera mística, puesto que no parece ser místico o inútil preguntar por las condiciones de la temporalización, es decir, no tanto por el peculiar "ser" que tenga el presente viviente, sino por la forma cómo son constituidas las vivencias.

2 „Zum Wesen der Selbsterinnerung gehört offenbar, daß das selbst-wiedererinnerte reine Ich als vergangenes bewußt ist, daß andererseits eine Blickwendung möglich ist, vermöge deren das reine Ich sich als reines Ich des Wiedererinnerns erfaßt, somit als selbstwahrgenommene aktuelle Gegenwart [...] (Hua IV, 101). "Ich bin mir aber auch nur insofern Gegenstand, als ich 'Selbstbewußtsein' habe, auch wenn ich nicht reflektiere. Hätte ich es nicht, dann könnte ich auch nicht reflektieren" (Hu IV, 318) 
No se trata tan sólo de que no pueda haber una dación evidente del yo en su operar actual porque el yo al que se dirige la reflexión no es el mismo que el yo reflexivo operante, sino que la cuestión es que aunque lo capte, no puede tener una dación adecuada de su operar en él mismo, sino sólo del conjunto de las daciones que son sus rendimientos. El único acceso es un acceso deductivo-regresivo. Beils carga las tintas sobre el hecho de que si la reflexión sobre el presente viviente quiere ser fenomenológica, tiene que haber efectuado previamente una exclusión o reducción en la que quedaba fuera de juego aquel sentido constituido en el presente viviente. Sin embargo, el presente viviente no puede ser pensado más que en virtud de lo constituido en él. Es por ello por lo que habla de una reflexión dialéctica (Beils 1987, 6).

A nuestro entender, esta formulación no es demasiado acertada. Cuando el yo reflexiona sobre sí mismo, sobre su ser presente viviente, se pseudo-advierte como aquello operante siempre activo que no puede ser ontificado, que no puede ser captado en la reflexión. Cuando atiende a los resultados de este movimiento, de esta presentación viviente, los capta como una serie de donaciones de sentido o objetos dados en el tiempo (inmanente) a los que le corresponden una serie de vivencias que son las actividades de ejecución que él mismo efectúa.

Cuando el presente viviente-fluyente vuelve sobre sí mismo, se ontifica en una ,conciencia transcurriente', es decir, se toma a sí mismo como tema y se ve ahora estructurado según las distinciones posibles de ahora, de lo que acaba de hacerse pasado y de lo que viene al mismo tiempo en su sucesión y cubrimiento (Brand 1955, 78).

\section{La "autotemporalización" del proto-yo}

En los manuscritos $\mathrm{C}$ se habla muy frecuentemente del yo que ejecuta los actos de conciencia. La denominación más habitual para este yo operante, previo al yo tal y como es captado en la reflexión inmanente en cuanto polo nuclear en torno al que se ordenan las vivencias, es proto-yo. La denominación protoyo es una forma para referirse al hecho de que el yo es una esfera de presencia viva anónima y primera a la que sólo se puede acceder regresivamente. La unidad de esta subjetividad trascendental o yo es una unidad que "trasciende" a cada una de las vivencias singulares de un modo particular: se trata de una unidad de ejecución, de una unidad del ser vividas las diferentes vivencias. Este yo anónimo tiene la facultad de, al mismo tiempo que en sí mismo se autotemporaliza de alguna forma, salir de sí mismo y "mostrarse" en el tiempo inmanente en cuanto sucesión de vivencias. 
De entrada es preciso reconocer que el apelativo proto-yo no puede dejar de ser una metáfora, puesto que no es posible precisar en qué sentido haya algo así como un proto-yo operante antes del yo que nos "propone" la reflexión: aunque se trate de una esfera de constitución originaria y de la mía propia, "no puede ser explicitada, es decir, demostrada intuitivamente en la reflexión" (Held 1966, 150) ${ }^{1}$ la participación de mi yo en ella.

En el manuscrito C7 se especula acerca de este peculiar movimiento mediante el que el protoyo anónimo se transforma en un yo insistiendo en que es un mismo proceso aquel mediante el que el yo se autotemporaliza y aquel en el que es constituido el mundo trascendente. Cuando el protoyo se aparece como un yo que dura, se aparece paralelamente un mundo como correlato dotado de duración. La relación entre el proceso del fluir temporalizante y el tiempo inmanente generado por aquel puede ser interpretada como la relación entre una "representación" y una "unidad representada" o como la relación entre una forma y un contenido (C7, 12a). El flujo primario de mi "yo soy", la vida primitiva efectúa una temporalización de sí misma en la reflexión.

Husserl reconoce más adelante que en realidad la dación de un protoyo no es tal dación sino que el concepto surge en base a la necesidad de suponer que al yo mundano le precede en el plano de la anonimidad un proto-yo correlato de las fuerzas afectivas que todavía no ejercen afección propiamente hablando. Es decir, el protoyo es un elemento que suponemos ya ahí antes en cuanto correlato necesario de las pre-unidades formadas, pero que no puede ser propiamente hablando objeto de ninguna dación reflexiva.

En el texto número 14 de los manuscritos de Bernau (Hu XXXIII) se afirmaba que el yo correlato de los actos no es ningún objeto, sino un polo supratemporal. La única forma de captarlo-temporalizarlo se debe al carácter temporal de las afecciones que lo afectan y de las acciones que él ejecuta, en parte en respuesta a estas afecciones. El yo es localizable en el tiempo gracias a que sus afecciones y acciones también lo son. En otros textos anteriores $(\mathrm{Hu} \mathrm{X})$ se sugería que el movimiento de temporalización de las vivencias de la conciencia interna es inseparable del movimiento de temporalización de los objetos apuntados por las vivencias de esta conciencia interna (doble dirección intencional de la retención - longitudinal y transversal, autoaparición del flujo a sí mismo). En los manuscritos $\mathrm{C}$ no se niega esta operación doble, sino que al introducirse el concepto de proto-yo se hace necesaria una nueva distinción que podemos ahora resituar "en el interior de la conciencia interna". Husserl comienza afirmando que es necesario separar radicalmente la temporalización de los datos pre-egoicos y la temporalidad de los proto-

' „In welchem Sinne von Ichbeteiligung ich hingegen auf meine eigene faktische und anonyme Funktionsständigkeit stoße, kann phänomenologisch nicht mehr explizit, d.h. reflexiv anschaulich aufgewiesen werden" (Held 1966, 150). 
-actos del proto-yo. Si es posible reflexionar sobre algo es porque reflexiono sobre algo de lo que previamente tenía conciencia en el modo de la vivencia, es decir, algo que ya estaba siendo vivido, "percibido internamente". La posibilidad de que se desarrolle una actividad y una afectividad presupone una corriente de vivencias en la que ya se está llevando a cabo cierta autotemporalización. Antes de las afecciones es necesario presuponer un yo-centro previo a cualquier proceso de temporalización inmanente como punto al que se dirigen una serie de fuerzas afectivas - y del que parten con posterioridad las acciones.

Todo operar del yo - Husserl emplea el término Aktus, para que no sea confundido con los actos situados en el tiempo inmanente (C10,13a) - está sujeto a un proceso de temporalización que se inicia con un protobrotar ( $U r$ quellen) y un fluir retencional continuos. Esta autotemporalización es diferente de la temporalización de los datos pre-activos. Se trata de cierto proto-yo operante encargado de ejecutar los modos de realización o ejecución de cada una de las fases de una vivencia, que precede a todas las vivencias temporalizadas. En el proceso de autotemporalización de cualquier operación de este proto-yo se distinguen: por una parte, una temporalización de esta operación en cuanto vivencia (impresiones, retenciones y protenciones); por otra, una serie de modos de ejecución correspondientes al proto-yo mismo, es decir, los estadios por los que atraviesa este proto-yo cuando ejecuta una vivencia.

Se inicia la ejecución de un acto. A nivel del proto-yo se trata de un poner-en-juego (Ins-Spiel-Setzen) el acto cuando este comienza. Posteriormente a nivel del proto-yo hay un modo de ejecución de continuación (Fortführung) cuando el acto está siendo ejecutado. Por último, cuando ha dejado de ser ejecutado no pierde de forma absoluta su validez sino que el protoyo lo mantiene "todavía asido" ("Noch im Griff"): el acto sigue valiendo, sigue contando y conserva su validez bajo la forma de una habitualidad sedimentada "[...] que a su modo sigue siendo en el ahora también realización" $(\mathrm{C} 10,16 \mathrm{~b}){ }^{1}$ Se trata de un modo de ejecución de durar o conservar la validez (Fortwähren). Tanto la conciencia impresional, como la conciencia retencional y protencional se unen en cada una de las diferentes ejecuciones a nivel del proto-yo. Por ejemplo: cuando el proto-yo pone-en-juego un acto (atiéndase al hecho de que Husserl utiliza aquí el término acto para referirse a cualquier vivencia al nivel de la ejecución operante egoica, proto-egoica, y no exclusivamente a un acto intencional), la conciencia que se tiene de la fase de la vivencia que le corresponde en el plano inmanente-objetivo es tanto impresional, como retencional, como protencional. Es por lo tanto muy importante distinguir claramente entre la dación de la vivencia, en la que co-intervienen impresiones, retenciones y protenciones, y el comenzar 
a ejecutarse, continuar siendo ejecutado, finalizar y conservar su validez de un acto:

Si todo esto es correcto, tendremos que distinguir en cada acto en su temporalización originaria en cuanto vivencia entre la impresión de la vivencia, así como las retenciones y protenciones de la vivencia, y los modos propiamente protobrotantes, en concreto en cuanto tipos de modos de ejecución, que le corresponden al proto-yo operante mismo. ${ }^{1}$

El proto-yo es aquel yo que ejecuta los actos. La temporalización sólo puede tener lugar una vez que un acto se constituye como una unidad temporal en el plano inmanente-objetivo, pero para que un acto se produzca es necesario un proto-yo situado fuera de este plano. Los modos de ejecución de la conciencia interna no coinciden con los modos de conciencia temporal: a cada uno de los primeros lo acompañan siempre los tres tipos de "conciencia" temporal. Frente a las protoimpresiones, retenciones y protenciones referentes a las fases de las vivencias se sitúa un "lado opuesto verdaderamente activo" (eigentliche aktive Gegenseite) (C10, 14b) formado por los modos de ejecución de esas vivencias por parte del protoyo. El protoyo pasa en su operar por una serie de modos de ejecución - "entrar en juego" (Einsatz), "conservar" (Fortdauern) y "mantener asido" ("Noch im Griff") - que son los que al nivel de las operaciones del yo permiten que una vivencia sea captada en la reflexión inmanente como una unidad temporal ordenada.

El yo en su originariedad originaria no está en el tiempo, en el presente autotemporalizante-temporalizado en cuanto presente viviente protomodal. Separamos en efecto en el yo el yo como centro de los rayos egoicos de afección y acción, de aquel que ya de antemano ellas [afección y acción] en cuanto unidades intencionales (o sea, objetos existentes) presuponen, como aquel del que parten las afecciones y al que se dirigen los actos. Pero según aquello que intentábamos aclarar no yace en todo este ámbito del ser temporalizado (y como sabemos, a su vez temporalizador en diferentes niveles) aquel yo que debe preceder a lo temporalizado en las vivencias temporalizadas del yo (C10, $14 \mathrm{a})^{2}$

1 „Ist das alles richtig, so werden wir scheiden müssen bei jedem Akte in seiner ursprünglichen Zeitigung als Erlebnis die Erlebnis-Impression bzw. die Erlebnisretentionen und -protentionen und die eigentlich urquellenden, auch ichlich quellenden Aktmodi, nämlich als Modi der Vollzugsweisen, die dem fungierenden Ur-Ich selbst zugehören“ (C10, 14a).

2 „Das Ich in seiner ursprünglichsten Ursprünglichkeit ist nicht in der Zeit, hier der beständig als lebendige urmodale Gegenwart sich zeitigenden-gezeitigten Gegenwart. Zwar scheiden wir in dieser das Ichzentrum der ichlichen Affektions- und Aktionsstrahlen, von dem, was 
La localización de este proto-yo nos lleva a distinguir en cada operación del proto-yo una temporalización del acto en cuanto que vivencia en la que colaboran necesariamente impresión, retención y protención; y unos modos de ejecución del acto egoico anteriores a la constitución de éste en cuanto vivencia inmanente.

Lo impresional, lo retencional y lo protencional forman (juntos) o les corresponde una unidad de ejecución. Hay un yo de las vivencias inmanentes y un protoyo puro situado fuera de la correlación con este flujo inmanente. Un yo temporal de las vivencias para el que esta se da como una unidad temporal y un proto-yo o yo-primigenio continuamente operante bajo diferentes modos de ejecución. Husserl afirma que la verdadera cara opuesta al flujo temporal de impresión, retención y protención es el "continuo" ser-activo del proto-yo. Es decir, el verdadero responsable de que se pueda realizar el movimiento de temporalización es este proto-yo "anterior" a las vivencias, que empieza, sigue ejecutando, finaliza y mantiene la validez de un acto.

En el terreno del protoyo tiene lugar una autotemporalización que transcurre en paralelo a la temporalización de las vivencias y está relacionada con las modalidades de realización de los actos: si se trata de un inicio, de una continuación o del final de la ejecución de un acto. Tras el inicio de la ejecución de un acto este entra en el terreno de las vivencias inmanentes del yo como algo pasado, pero los modos de ejecución del proto-yo que le van correspondiendo a este acto también entran a formar parte de un cierto sucederse de los modos de ejecución del protoyo en cuanto un proto-pasado. De acuerdo con lo anterior, cuando se reflexiona sobre la temporalidad de un acto intencional se pueden realizar las siguientes distinciones: 1. En primer lugar, una capa inferior formada por aquello temporal del objeto al que se refiere el acto: es decir, el contenido material inmanente-objetivo a qué se refiere el acto. 2. En segundo lugar, en un plano superior, el acto en cuanto que acto inmanente temporal, es decir, la unidad formada por una serie de fases de la vivencia. A cada una de las fases de este acto le corresponde un modo diferente con el que es ejecutado por el proto-yo operante. 3. En último lugar, un proto-yo ejecutante del acto que se aparece en el tiempo inmanente como un yo correlato de los actos. Dentro de este último nivel el propio yo que reflexiona puede también captarse a sí mismo, aunque como situado en el tiempo inmanente. Lo más importante es advertir como en el último nivel el acto ejecutante mismo no se aparece tal y como es ejecutado

sie immer schon als die intentionalen Einheiten (bzw. seiende Gegenstände) voraussetzen, als $<$ das $>$ wovon die Affektionen ausgehen, und auf das die Akte sich richten. Aber nach dem, was wir uns klar zu machen versuchten, liegt in diesem ganzen Reich des gezeitigten (und wie wir wissen, selbst wieder in Stufen zeitigenden) Seins nicht dasjenige Ich, das dem Gezeitigten in den gezeitigten Icherlebnissen vorangehen muss" (C10, 14a). 
por el yo, sino que sufre una cierta "transformación" que lo introduce en el plano inmanente. El yo operante se temporaliza inmanentemente, pierde su calidad de presente vivo en el momento en que es captado como un yo correlato de las vivencias. En sí mismo el yo operante es un polo carente de duración, una estructura que permanece idéntica a sí misma a través de todas. las diferentes ejecuciones o realizaciones que lleva a cabo: "un ahora que permanece y que se queda" que no puede ser comparado con el yo que acompaña a la corriente inmanente de vivencias.

Todo se temporaliza como algún tipo de cosificación, también el yo operante y la secuencia de sus ejecuciones, incluso el $\langle$ yo $\rangle$ que conserva en cada fase del acto todas las fases retencionales pasadas en el modo de la ejecución y que así las conserva egoicamente [...]. ¿Pero no se advierte también en esta temporalización, que el yo que permanece y que queda no es algo que dure durante el acto como una duración temporal cumplida en el mismo sentido en que dura algo temporal, sino que frente a la duración cósica es algo idéntico y sin extensión, un ahora que permanece y que queda a través del cambio de sus ejecuciones $(\mathrm{C} 10,17 \mathrm{~b}){ }^{1}$

El yo operante no deja de ser nunca algo que opera continuamente en la pura actualidad. Este yo que ejecuta no se temporaliza, sino que lo que se hace pasado es el yo temporalizado inmanentemente, el yo del que se tiene conciencia. El yo ejecuta en el presente los "todavía-mantener-la validez" de las fases de los actos y de los actos pasados y un apuntar a las fases futuras. Este yo es un yo que dura, pero no en el sentido de una duración material, sino en el sentido de un yo carente de extensión, un yo que permanece y que sigue siendo el mismo en el transcurso de sus ejecuciones (Vollzüge), un yo que consiste en el ejecutar o conservar el conjunto total de sus ejecuciones.

\section{Los procesos de constitución pasiva. La discusión en torno a la inten- cionalidad.}

En vista de todo lo anterior se hace comprensible la de entrada extravagante afirmación husserliana de que el presente protofluyente entendido en cuanto esfera inmanente es ya no-yo: no-yo en el sentido de que resulta de

1 „Ja alles verzeitlicht sich in einer Art Versachlichung, auch das vollziehende Ich und die Folge seiner Vollzüge, selbst dass in jeder Phase des Aktes alle bisherigen retentionalen Phasen im Vollzug haltende und so ichlich behaltende <ich> [...]. Aber sieht man nicht auch in dieser Verzeitlichung, dass das stehende und bleibende Ich während des Aktes nicht ein durch den Akt als erfüllte Zeitdauer hindurch in gleichem Sinn dauerndes ist, wie ein Zeitliches dauert, sondern dass es selbst ausdehnungslos während der sachlichen Dauer Identisches ist, stehendes und bleibendes Jetzt im Wandel seiner Vollzüge?" (C10, 17b). 
un movimiento más originario que es el de los modos de ejecución del proto-yo. Los diferentes niveles constituidos en el presente fluyente originario son algo no-yo en la medida en que no son la operación ejecutante en que consiste en realidad él mismo. El proto-yo constituye los diferentes niveles permaneciendo "fuera" de ellos, algo que no niega que el proto-yo se aparezca como algo temporalizado en cada uno de estos niveles.

El tiempo es así una forma de coexistencia de los elementos pertenecientes a cada uno de estos niveles, sin que esta forma se vea determinada por ninguno de los contenidos para los que es forma. El propio fluir de la corriente de conciencia originaria es el que genera esta forma. Esto implica que en el más bajo de los niveles ya se puede hablar de una especie de pre-tiempo o pre-temporalidad correspondiente a los pre-entes situados en él.

Todo eso es una 'constitución' no-egoica captada y que tiene lugar. Pero esta no se realiza en el aire. Todo este acontecer protofluyente no es un acontecer muerto, sino que una 'operación' egoica es el motor más interno. La afección egoica tan abundantemente temporalizada en este proceso y el múltiple tejido de los actos del yo, todo eso, tal y como se aparece en la cosificación, no son la operación egoica primitiva, que nosotros desde luego coentendemos siempre desde luego de forma no atenta y que donde hablamos de formaciones surgidas activamente siempre realizamos como algo subyacente $(\mathrm{C} 10,15 \mathrm{a} / 15 \mathrm{~b}){ }^{1}$

Antes de las afecciones y de los actos del yo hay una "actividad" previa de un proto-yo que genera la forma de coexistencia gracias a la que entran en el plano inmanente estas afecciones y estos actos en virtud de sus modos de ejecución. Antes de toda objetivación, mundanización, materialización, hay un proto-yo que actua como una especie de "motor interno" responsable de la peculiar "constitución" de los niveles, un movimiento de flujo del que resultan los diferentes niveles.

Pero además del movimiento del proto-yo también se hace necesario presuponer un movimiento de aquello que es "no-proto-yo", de una esfera hilética no-yoica donde tiene lugar la temporalización de la que resultan las pre-unidades hiléticas, donde se constituyen ciertas proto-objetividades. La conclusión final es que es necesario presuponer dos movimientos de temporalización separados situados antes del plano mundano:

1 „All das ist nicht-ichlich statthabende und erfasste ,Konstitution'. Aber diese steht nicht in der Luft. Dieses ganze urströmende Geschehen ist nicht totes Geschehen, sondern ichliche "Leistung" ist der innerste Motor. Die darin so reichlich gezeitigte ichliche Affektion und das mannigfaltige Gewebe der Ichakte, all das, so wie es in der Versachlichung auftritt, ist nicht die urtümliche ichliche Leistung, die wir freilich unvermerkt stets mitverstehen, und, wo wir von aktiv entsprungenen Gebilden sprechen, stets mit unterlegen (C10, 15a / 15b). 
En conclusión: la constitución de aquello que es de los diferentes niveles, de mundos, de tiempos, tiene dos protocondiciones, dos protofuentes que temporalmente hablando (en cada una de estas temporalidades) siempre le "sirven de base" a aquella: 1) mi yo primordial en cuanto operante, mi proto-yo en sus afecciones y acciones, con todas las estructuras esenciales de los modos correspondientes, 2) mi primordial no-yo en cuanto corriente primitiva de temporalización y también en cuanto protoforma de la temporalización, constituyendo un campo temporal, aquel de la proto-objetividad. Pero ambos protoprincipios son uno, inseparables y abstractos si son considerados cada uno por sí $(\mathrm{C} 10,15 \mathrm{~b}){ }^{1}$

Husserl insiste en que no puede pensarse en un universo hilético constituidor, un protoacontecer temporalizador-temporal previo a toda participación del yo. Incluso a la absoluta pasividad, al puro generarse de unidades hiléticas, que tiene lugar gracias al cubrimiento sintético entre diferentes retenciones dirigidas a un mismo núcleo hilético, tiene que acompañarlo cierto protoyo para el que sus fuerzas afectivas tengan sentido $(\mathrm{C} 10,16 \mathrm{a})$.

El tercero de los manuscritos $\mathrm{C}$ reconduce la cuestión al nivel en el que se constituyen pasivamente las vivencias a partir de las daciones hiléticas. Insiste en varias ocasiones en el hecho de que el análisis se ve constantemente reconducido a lo no-yoico y a la constitución pasiva de los datos de sensación en la esfera hilética. La formación de un presente concreto es explicada en términos de una asociación unificadora o fundición, formación de unidad en el ahora primario de la que resulta un dato (Datum) presente. Se trata de fundiciones que se basan sobre relaciones de semejanza establecidas entre diferentes daciones hiléticas.

La definición más precisa que se puede ofrecer de los datos hiléticos es que se trata de aquello resultante del contacto con lo no-yoico: el primer sentir procedente de la apertura de un yo al mundo. Esta hyle es algo indeterminado, algo fáctico pre-donado pasivamente sin que sea necesaria ninguna intervención por parte del yo. Husserl afirma que un determinado curso cinestésico del yo "condiciona" ("bedingt") un transcurso en el nivel de la esfera hilética pura donde a partir de diferentes núcleos hiléticos se forman una serie de unidades hiléticas a través de las leyes de asociación de semejanza. El empleo de las comillas deja entrever que no se trata aquí de afirmar que los cambios en la mirada o en la orientación corporal, por ejemplo, mo-

1 „Also: Konstitution von Seienden verschiedener Stufen, von Welten, von Zeiten, hat zwei Urvoraussetzungen, zwei Urquellen, die zeitlich gesprochen (in jeder dieser Zeitlichkeiten) immerfort ihr ,zugrundeliegen'; 1) mein urtümliches Ich als fungierendes, als Ur-Ich in seinen Affektionen und Aktionen, mit allen Wesensgestalten an zugehörigen Modis, 2) mein urtümliches Nicht-Ich als urtümlicher Strom der Zeitigung und selbst als Urform der Zeitigung, ein Zeitfeld, das der Ur-Sachlichkeit, konstituierend. Aber beide Urgründe sind einig, untrennbar und so für sich betrachtet abstrakt" (C10, 15b). 
tiven cambios en la organización del campo sensible externo. Este "determina" debe ser interpretado como un "le acompaña". Lo que se afirma es que acompañando a estos cambios cinestésicos se dan continuamente "sucesivas" multiplicidades hiléticas que se muestran como un campo hilético coexistente formado en virtud de una relación de asociación pura, en la que todavía no ha intervenido ninguna síntesis de cubrimiento, semejanza, contraste o homogeneidad.

En la esfera inmanente [inmanente denomina aquí aquello que anteriormente era considerado estrictamente ingrediente] se produce la constitución de objetos no-inmanentes; un curso puesto en escena por el yo, un curso cinestésico 'determina' un curso en la esfera más inferior, la esfera puramente hilética, cuyos campos hiléticos son campos de coexistencia formados a través de una asociación pura $(\mathrm{C} 3,41 \mathrm{~b})$. $^{1}$

Se trataría de una pasividad yoica que precedería a toda actividad, a todo acto del yo: la capacidad de recibir el estímulo externo. En el manuscrito C6 se distinguen dos sentidos de intencionalidad. El presente viviente constituye los objetos inmanentes a través de una "intencionalidad pasiva". Además de este tipo hay una segunda intencionalidad que sería aquella con la que el yo se dirige espontáneamente a sus objetos en cualquiera de sus actos. Husserl advierte aquí que la denominación intencionalidad en el caso de la "intencionalidad pasiva" tiene que ser aceptada de una forma "sui generis" puesto que la aclaración de qué sea exactamente la "intencionalidad pasiva" es todavía un problema a resolver. De momento, Husserl afirma que puede ser caracterizado como intencional el proceso de formación de un dato hilético a partir de diferentes núcleos o daciones puntuales hiléticas. También son intencionales las apariciones o fenómenos en relación al objeto que se aparece. Además, existe la intencionalidad propiamente dicha, intencionalidad en el sentido de un acto intencional, de un dirigirse del yo a un objeto atribuyéndole una posición dóxica. A nivel perceptivo, antes de las intencionalidades de acto del yo, es necesario suponer que se generan una serie de unidades hiléticas que lo afectan y que se forman mediante procesos pasivos de cubrimiento en los que ya intervienen retenciones, protenciones e impresiones. Estas unidades hiléticas se constituyen retencionalmente gracias a la relación de coincidencia que se produce entre diferentes núcleos hiléticos, es decir, su unidad se forma gracias al hecho de que diferentes

' „In der immanenten Sphäre vollzieht sich die Konstitution von nicht-immanenten Gegenständen; ein vom Ich inszenierter, also kinästhetischer Verlauf "bedingt" einen Verlauf in der alleruntersten, der rein hyletischen Sphäre, die in ihren hyletischen Feldern durch pure Assoziation ein Feld der Koexistenz ist" (C3, 41b). 
núcleos coinciden unos con otros y se fusionan. El resultado de la afección de estas unidades sobre el yo son las diferentes vivencias.

Husserl afirma en el manuscrito $\mathrm{C} 10$ que esta intencionalidad pasiva no es propiamente ningún tipo de "intención" en sentido propio. El mero fluir de la conciencia por sí mismo sólo constituye pre-entes, pre-unidades que necesitan de un proceso de identificación activa y de rememoración para transformarse en verdaderos objetos / unidades temporales al mostrarse como siendo siempre las mismas y ocupando la misma posición temporal. Estas pre-unidades (hiléticas) surgen a través de una unificación pasiva y una vez constituidas están dotadas de la capacidad de afectar, tienen fuerza afectiva, aunque en un primer momento todavía no se trate de datos hiléticos propiamente dichos.

Reflexionando regresivamente se hace necesario suponer que a la actividad del yo le precede una constitución o temporalización pasiva de una serie de pre-entes. Estas pre-unidades son el resultado de una temporalización pasiva. Aunque los datos hiléticos sean captados propiamente cuando afectan al yo, es posible llevar a cabo una "des-nivelación regresiva" (regressive Abschichtung) mediante la que se advierte que estos datos eran unidades ya previamente temporalizadas de forma pasiva:

Regresivamente retornamos paso a paso a la más inferior constitución de unidades en cuanto pre-entes (al universo de lo pre-ente) [...] Este universo de la inactividad (pasividad en un sentido determinado) es 'presupuesto' por la actividad concreta, ya siempre operante del yo activo, que es apercibido ahí como siendo - como temporalización pasiva de lo pre-ente $(\mathrm{C} 10,5 \mathrm{a})$.

Paralelamente a la constitución pasiva de estas pre-unidades hiléticas tiene que producirse la constitución pasiva de un yo para el que estas son correlato. En este nivel pre-óntico se puede distinguir entre las pre-unidades hiléticas y un yo anónimo para el que se dan estas pre-unidades con una determinada fuerza afectiva. Algunas de estas pre-unidades consiguen sobrepasar cierto umbral de afección y originan la aparición de una serie de objetos a los que le corresponden una serie de vivencias a nivel egoico.

Husserl considera dos opciones teóricas posibles. Puede pensarse si el proto-yo es siempre afectado cuando se produce un destacamiento (Abhebung) de alguna fuerza afectiva en el campo hilético - algo que implicaría que cualquier elemento destacado tendría que ser capaz de afectar - o si existen destacamientos que no implican ninguna afección. Tras numerosas dudas Husserl considera en este pasaje más plausible la consideración de que no todo destacamiento tiene que generar una verdadera afección. El destacamiento es tan sólo un primer "incremento de fuerza" (Kraftzuwachs), que puede ser posteriormente explicitado como una afección parcial y todavía más tarde ser objeto de un dirigirse atentivo por parte del yo. Son posibles 
formaciones pre-ónticas hiléticas que no afectan en acto al yo, sino que se trata de fuerzas potencialmente afectivas.

Husserl planteaba en los manuscritos de Bernau un regreso al infinito provocado por la afección. El paso de una fuerza afectiva al terreno de la atención se efectúa en un determinado punto concreto. En este determinado punto el yo comienza a atender a la afección: hay una tendencia del yo que hace que una determinada afección entre en el campo de la atención. El problema es que esta tendencia pertenece al campo de lo todavía no captado atentamente por el yo, pertenece a la esfera de lo no atendido. Se necesitaría entonces una tendencia consciente de otro nivel que justificase por qué a partir de determinado momento esta tendencia entra en el campo de lo aprehendido, y así sucesivamente al infinito:

[...] acerca de las tendencias afectivas (la tendencia, la atracción sobre el yo a reaccionar volviéndose hacia..., la capto como algo notable en la reflexión; no es ninguna mera façon de parler) es cuestionable si ellas mismas son algo perteneciente necesariamente al segundo plano. ¿Pero deberían entonces las tendencias (como algo notable) conllevar tendencias de un nuevo nivel, y estas a su vez otras y así al infinito? (Hu XXXIII, 285). ${ }^{1}$

En los manuscritos de Bernau este problema era simplemente expuesto y no recibía ninguna solución. En los manuscritos $C$ vuelve a aparecer este tipo de regreso al infinito en relación a la relación del proto-yo con aquello pre-óntico que lo precede. El contacto con lo pre-óntico que ejerce fuerzas afectivas sobre el proto-yo sin ser todavía afección no puede ser conocido sino se supone algún tipo de pseudo-afección (ejercida sobre el proto-yo). Pero acerca de esta misma pseudo-afección tampoco podríamos saber nada si esta no fuese pre-constituida (y afectase a un cierto proto-proto-yo). Y así sucesivamente. Se produce de nuevo de esta forma un regreso al infinito.

Ahora bien, naturalmente no podríamos saber eso, si, aunque ello mismo pre-siendo, no hubiese sido constituido y no hubiese podido afectar también a su manera al mismo polo-yo convirtiéndose en objeto temático- y así al infinito. Por lo tanto, la autoconstitución de la subjetividad trascendental conduce a los

1 „[...] für die affektiven Tendenzen (den Zug, die Anziehung auf das Ich, im Zuwenden zu reagieren, erfasse ich als ein selbst merkliches in der Reflexion, es ist keine bloße façon de parler) fragt es sich, ob sie etwas notwendig zum Hintergründlichen Gehöriges sind. Aber müsste dann nicht auch die Tendenzen (als ein Merkliches) Tendenzen neuer Stufe mit sich führen, und dieses wieder und so in infinitum?" (Hu XXXIII, 285). Con tendencias afectivas se refiere Husserl a aquello que hemos sistemáticamente denominado fuerzas afectivas. 
bonitos regresos al infinito con los que intentaba terminar ya en Bernau (C10, $6 \mathrm{~b} / 7 \mathrm{a}){ }^{1}$

En un determinado momento del manuscrito 15, tras haber iniciado un análisis de las síntesis progresivamente más complejas en que se ve envuelta la hyle, Husserl interrumpe su investigación y afirma estar insatisfecho con este estudio por haber partido precisamente del concepto operativo de hyle. Esta reacción parece ser una especie de recordatorio a que la fenomenología se define a sí misma como un estudio que efectúa reducción de todo aquello situado más allá de la conciencia inmanente. Parece que habría que iniciar de nuevo la reflexión practicando una epoché para reducirse exclusivamente al análisis del flujo originario temporal independientemente de toda materia.

En este proceder se había presupuesto que ya habríamos preguntado acerca de la hyle y la asociación era pensada como creadora de campos hiléticos y de unidades en ella, como unidora de los campos hiléticos unos con otros, etc. Pero habría sido ante todo necesario proceder de forma concreta y considerar la asociación como el título general para la formación de unidad, como aquello que genera la unidad de la corriente, la temporalización, en todos los niveles, es decir, en cuanto título para todo aquello que la constitución de „lo que es“ ya presupone - ¡constitución a través de la actitividad del yo! En el proceder concreto no se sabe nada de la hyle, sino que lo primero es el fluir concreto primordial y permaneciente que puede ser alcanzado mediante la epoché. Así se empezará de nuevo $(\mathrm{C} 15,4 \mathrm{~b}){ }^{2}$

En vez de referirse a los procesos pasivos de organización de la hyle Husserl quiere retomar el análisis atendiendo a las configuraciones o ejecuciones del yo, independientemente de los diferentes grados de organización asociativa de los datos hiléticos. El problema es que pese a esta protesta sus análisis se topan siempre con el nivel más fundamental de la proto-intencio-

1 „Nun könnten wir das natürlich nicht wissen, wenn es, obschon selbst vorseiend, nicht konstituiert wäre und somit in seiner Weise ebenfalls das Ich, denselben Ichpol affizieren könnte und thematisch werden könnte - und so in infinitum. Also die Selbstkonstitution der transzendentalen Subjektivität führt auf die schönen unendlichen Regresse, $<6 \mathrm{~b}\rangle$ mit denen ich schon in Bernau fertig zu werden versuchte" (C10, 6b/7a).

2 „In diesem Gang war vorausgesetzt, dass wir schon auf die Hyle zurückgefragt hätten, und die Assoziation war als hyletische Felder und in ihnen Einheiten bildend gedacht, als hyletische Felder miteinander verbindend etc. Aber es wäre vor allem nötig gewesen, konkret vorzugehen und Assoziation als den allgemeinen Titel der Einheitsbildung zu behandeln, der überhaupt Stromeinheit, Zeitigung leistet in allen Stufen, also Titel für all das ist, was die Konstitution von "Seiendem" schon voraussetzt - Konstitution durch Ichaktivität! Im konkreten Vorgehen weiß man nichts von Hyle, sondern das Erste ist die von der Epoché aus zu erreichende konkrete urtümliche, stehende Strömung. So wird also neu angefangen" $(\mathrm{C} 15,4 \mathrm{~b})$. 
nalidad pasiva o temporalización pasiva de unidades, pre-entes. Parece inevitable confirmar que aquí se alcanza finalmente un dualismo, que nos parece insalvable, entre lo no egoico y lo egoico, entre la hyle múltiple e informada y las vivencias en cuanto unidades inmanentes, entre la pre-temporalización en la que se genera el pre-ser del mundo pre-hilético y la proto-temporalización egoica. Pese a que Husserl insista en el hecho de que estos dos principios fundamentales o principios originarios están unidos y no pueden ser separados, todavía tendría que matizar como es posible la unión de ambos fundamentos, ante el más que probable riesgo de que la cuestión reconduzca a un dualismo insuperable entre un protoyo y un no-protoyo. De hecho, intentando solucionar este problema Husserl introduce en el manuscrito $\mathrm{C} 15$ el concepto de sensación (Gefühl), como un elemento bisagra situado entre la esfera hilética y la esfera egoica. Se trataría de suponer que todo lo protohilético, es decir, todo lo que todavía no es propiamente un dato hilético que afectạ, se reproduce en el plano egoico con absoluto paralelismo. "Observemos la cosa más atentamente. Intentemos quedarnos con el hecho de que la configuración del "contenido" de la esfera protohilética-inmanente determina la sensación" (C16, 68b). ${ }^{1}$

Retomemos el problema de la intencionalidad pasiva. Husserl se refiere a sus propias teorizaciones anteriores para afirmar que hasta ahora se había interpretado la diferencia entre intencionalidad pasiva y activa como una diferencia entre dos modos de ejecución de una misma intencionalidad. En algunos manuscritos de Bernau se afirmaba que la diferencia entre la dirección intencional propia de los actos en los que el yo se ve envuelto activamente y la intencionalidad pasiva que los precede es una diferencia de la modalidad de realización o ejecución (Vollzugsmodalität) de la intención constitutiva. En otras palabras, la "constitución" de unidades hiléticas pre-objetivas realizada pasivamente por el flujo originario se convertiría en una constitución propia cuando el yo se dirigiese activamente a esta constitución en una reflexión. La intencionalidad pasiva, aquella que continuamente opera formando objetos que vienen a situarse en un "segundo plano" de objetos no captados activamente, se transformaría mediante un cambio en su modo de ejecución en una intencionalidad egoica, activa (C10, 18a). En los manuscritos $\mathrm{C}$ se pasa a considerar que la distinción entre los modos de ejecución de un acto tiene sentido únicamente dentro de la esfera del yo activo: no es posible considerar que hay un modo de ejecución de una intencionalidad activa mediante el cual esta puede ser considerada una intencionalidad pasiva. El concepto de modo de ejecución (pasiva o activa) es aplicable a las ejecuciones del yo, a sus actos, pero no a los procesos que ocurren en la es-

1 „Indessen sehen wir uns die Sache näher an. Bleiben wir dabei, versuchen wir es, dass in der urhyletischen-immanenten Sphäre das Inhaltliche in seiner Konfiguration das Gefühl bestimmt" $(\mathrm{C} 16,68 \mathrm{~b})$. 
fera hilética. En cualquier caso que se hable de una objetualidad que es constituida a partir de una actividad estamos ante una intencionalidad activa, ante un modo de realización de un yo activo. No es posible afirmar que de forma previa ya se estaría produciendo la misma actividad constitutiva aunque bajo un modo de ejecución pasivo. Los cambios en el modo de realización se producen siempre dentro del campo de las actividades del yo, porque todo modo de realización, incluso el modo de ejecución que le corresponde a una experiencia del segundo plano, es el resultado de una proto-constitución ideal: ideal en el sentido de que esta proto-constitución no puede ser propiamente hablando captada, sino que se trata de un presupuesto necesario motivado por la necesidad de suponer que antes de reflexionar sobre un acto este está siendo ejecutado por un protoyo de forma anónima. Toda experiencia, todo modo de realización, implica una reactivación de un modo de realización anterior: re-activación, es decir, volver a activar algo que es pre-activo.

Donde la objetualidad es ya constituida a partir de actividad (mundo), tenemos de hecho un cambio en los modos de ejecución, puesto que en toda experiencia tiene lugar una reactivación y toda 'experiencia del segundo plano' de modo sedimentado está en una protoconstitución ideal $(\mathrm{C} 16,18 \mathrm{a}){ }^{1}$

Toda experiencia del yo es concebida como una actividad incluso antes de que se convierta en una constitución ejecutada propiamente por el yo. En el caso de la "constitución" a partir de la que resultan los datos hiléticos no se podría hablar de ninguna intencionalidad, ni activa ni por activar.

En el manuscrito C16 se propone un sentido estricto y un sentido lato en el que se puede realizar una constitución intencional. El primero se refiere a los actos intencionales habituales; el sentido lato, a la validez que tienen estos actos una vez que ya han sido realizados, al "todavía-valer" (Nochgeltung) de estos actos, al hecho de que no se convierten en una mera nada, sino que todavía siguen teniendo algún tipo de validez para el yo, aunque ya no sean "retenidos" activamente: actos en el modo de la sedimentación. No se trata de una retención referida a la esfera hilética sino a la retención de una actividad que ya ha sido realizada y que ya no es retenida activamente, una habitualidad sedimentada. Por lo tanto, ninguno de estos dos modos de intencionalidad recoge la anteriormente denominada intencionalidad pasiva. En este mismo manuscrito C16 se habla de una protención yoica que precede al yo propiamente dicho y que se cumple antes del operar activo de éste. Se trata de un cierto "instinto" egoico: "La supuesta protención y el cumpli-

1 „Wo die Gegenständlichkeit aus Aktivität konstituiert ist (Welt), da haben wir in der Tat Änderung der Vollzugsmodi, da in jeder Erfahrung eine Reaktivierung statthat und jede "Hintergrunderfahrung" sedimentierter Modus ist in einer ideellen Urkonstitution" (C16, 18a). 
miento mediante proto-impresión situados 'al inicio' y 'antes' de la constitución genética serían entonces el instinto egoico" $(\mathrm{C16}, 67 \mathrm{~b}){ }^{1}$ Aunque todo cumplimiento y toda aspiración a cumplimiento propios se producen en la esfera del yo, en cuanto que se trata de una aspiración a cumplimiento esta protención podría ser considerada algún tipo de intencionalidad, una intencionalidad pasiva. El problema es que en otros manuscritos la noción de cumplimiento aparece estrictamente asociada al dominio del yo. En el C13 se habla del cumplimiento como aquello que permite que se forme la unidad de los actos egoicos $(\mathrm{C} 13,20 \mathrm{~b})$. Si no hay ninguna intencionalidad pasiva ello es porque ahora todo lo intencional se considera egoico, sea algo intencional activo o intencional pasivo - reactivable.

El suplemento número XIII del volumen XXXIV de Husserliana comienza insistiendo en la necesidad de distinguir teoréticamente entre las unidades pretemporales (actos o unidades hiléticas) y las partes del flujo correspondientes a estas ụnidades. La cuestión central es aquí averiguar cuál es la diferencia entre la pre-intencionalidad de la corriente temporalizadora y la intencionalidad de los actos constituidos mediante esta pre-intencionalidad. En momentos anteriores de su pensamiento Husserl defiende la idea de que la pre-intencionalidad o intencionalidad pasiva de la corriente (Stromintentionalität) y la intencionalidad de acto del yo serían dos intencionalidades que se diferenciarían exclusivamente por ser dos modos de realización (Vollzugsmodus) de una misma intencionalidad. Concretamente, en algunos manuscritos de Bernau el flujo temporal absoluto era comprendido como no-intencional por sí mismo, aunque se apareciese a la reflexión como un flujo constituidor de objetos temporales. El flujo de conciencia se le aparecía a la reflexión como siendo constituidor de unidades temporales, aunque en sí mismo estuviese siempre "funcionando", transcurriendo sin ser constituidor (Hu XXXIV, 198). Como se observará en el siguiente apartado, Husserl terminará rechazando la noción de una intencionalidad pasiva. Si se atiende a la nueva descripción de cómo se constituye una unidad en el tiempo inmanente, se comprobará como no se trata de ningún proceso intencional.

Held considera que dentro de la pasividad pueden ser distinguidas dos esferas: la pasividad que configura unidades hiléticas a partir de los estímulos afectivos (pasividad egoica en la medida en que esta unidad es el resultado de alguna actividad egoica asociativa o sintética que podría ser influida por tendencias egoicas - por ejemplo, sus intereses práxicos-) y la pasividad totalmente pasiva del fluir de la fase impresional, la retención y la protención. A nivel del proto-yo cierto movimiento del dejar fluir (Entströmenlassen) tiene que anteceder al "todavía-mantener-asido" egoico de aquello que se escapa (Entgleitenden) $(1966,27 / 28)$. El flujo pasivo no puede ser un movi- 
miento totalmente no-yoico, sino que consistiría en algún dejar-fluir. Aún siendo cierto que la conciencia absoluta, es decir, el flujo pre-temporal, constituye pasivamente y de una forma no-intencional o no propiamente intencional una serie de vivencias que en la reflexión son captadas como intencionales en sentido propio, no se puede afirmar que toda la constitución proceda de un trabajo activo del yo. Es cierto que en toda constitución participa el yo, pero esto no implica que tenga que ser entendida como un trabajo (Leistung), sino que se trata de una participación pasiva, una participación en la que la corriente de conciencia se configura como tal por sí misma. Husserl afirma: "'Pasivamente' quiere decir aquí: sin ningún hacer yoico, sin que esté dirigido a realizarse, sin que se realice a partir de un hacer. No se trata de nada hecho, de ningún hecho (en sentido amplio)" (Hu XV, 179 / C17, $63 a-63 b)^{1}$

\section{Acerca del presente viviente. Última aportación en torno a la tempo- ralización pasiva.}

Los últimos textos que serán estudiados dentro de este artículo dedicado a la cuestión del tiempo en los manuscritos C son los pliegos 62-67, que ya habían sido publicados en $\mathrm{Hu}$ XXXIV, 179-183, y que forman parte del manuscrito $\mathrm{C} 17 .^{2}$ Con excepción de dos añadidos realizados en el año 1932 todos los pliegos fueron redactados en el verano de 1930. Nuestro análisis se detiene en aspectos que ya han sido tratados en repetidas ocasiones pero pretende ofrecer a modo de cierre una exposición sistemática de lo que significa la temporalización en los manuscritos C. Este último apartado estudia el texto número 10 del volumen XXXIV de Husserliana, que se titula "Acerca del presente viviente. Temporalización pasiva del flujo de conciencia frente a la temporalización de los actos. Pretemporalización y temporalización en sentido propio" y toma como punto de partida un yo entendido como centro de un "fondo pasivo clandestino" (Passive Untergrund) en el que se temporalizan todos los actos que efectúa el yo y todas las afecciones que recibe. Los significados de „Untergrund“ son varios: 1. subsuelo, 2.

1 "'Passiv" besagt hier: ohne Tun des Ich, als ob es darauf gerichtet wäre, es zu verwirklichen, als ob es sich verwirklichte aus einem Tun. Es ist also kein Getanes, keine Tat (im weitesten Sinn)“ (Hu XV, 179 / C17, 63a-63b).

2 Los pliegos 62a-63b (Hu XXXIV, 179,2 - 180,10) y los pliegos 65a-67b (Hu XXXIV, 180$-10-183,13)$ aparecen publicados como el texto número 10. Los pliegos 64a-b (Hu XXXIV, 183,18 - 184,32) aparecen publicados a continuación como el suplemento XIII. El pliego $67 \mathrm{~b}$ consta de tres hojas. Entre la primera y la segunda Husserl colocó el pliego 64 como suplemento a la segunda hoja. Por ello el pliego 64 aparece en la edición de $\mathrm{Hu}$ XXXIX después del 67b, publicado como suplemento XIII. De cara a nuestro análisis seguiremos el orden de los textos tal y como fueron publicados en Husserliana. 
(Hintergrund) fondo, 3. clandestinidad; (in den Untergrund gehen): a la clandestinidad. La traducción que proponemos, si bien es un tanto arriesgada, resulta apropiada si pensamos en que la vida pasiva del proto-yo transcurre en gran medida clandestinamente. Este "fondo pasivo clandestino" sería una especie de "conciencia"-de (entre comillas en el texto original) en la que a través de protoimpresiones, retenciones y protenciones se constituye la unidad de cada vivencia. Si se tratase de un acto este estaría dotado a su vez de la intencionalidad correspondiente a una "aparición sensible" (sinnliche Erscheinung) en la.que se aparece un objeto. En una nota a pié Husserl afirma que toda parte que se puede distinguir en la corriente de conciencia constituye una unidad hilética o un acto, consistiendo la diferencia entre ellos en la intencionalidad de la que están dotados los actos.

Toda parte de la corriente que se destaca en la corriente universal constituye una unidad, hilética, 0 un acto. A todo acto le corresponde un tramo de la conciencia de corriente, pero esta unidad 'acto' es ella misma de nuevo 'conciencia'-de. Pero de igual forma toda 'aparición-de' (Hu XXXIV, 179; C17) ${ }^{1}$

Las intenciones de los actos son "las intenciones en sentido propio", mientras que en la esfera pasiva está en juego una cierta pseudointencionalidad. La constitución de las unidades o de los actos (las conciencias-de en forma de actos o las afecciones que desencadenan las unidades hiléticas) son el resultado de una "intencionalidad pasiva", de una "temporalización" pasiva de la que resultan algo así como un pre-tiempo y un pre-ser. Este pre-tiempo está formado por las pre-unidades hiléticas generadas a partir de las relaciones pasivas de coexistencia y de sucesión establecidas entre ciertos núcleos hiléticos destacados previamente. La formación de estas pre-unidades todavía no implica una primera puesta en juego de los diferentes momentos "pasado", "presente" y "futuro", en cuanto que se trata de pre-unidades formadas por diferentes fases que "coexisten" o que se "suceden" según el movimiento pasivo a lo largo de la "corriente de vivencias" (de nuevo entre comillas puesto que no se trata de vivencias en el sentido de vivencias como unidades inmanentes, sino de protovivencias). Este movimiento de la corriente de conciencia es pasivo - no es el producto de ninguna actividad espontánea del yo -, aunque, como ya se ha afirmado, se trate de una pasividad egoica.

1 „Jeder sich im universalen Strom abhebende Stromteil konstituiert eine Einheit, hyletische, oder Akte. Jedem Akt enstpricht also eine Strecke des Strombewusstseins, aber diese Einheit ,Akt' ist selbst wieder ,Bewusstsein'-von. Ebenso aber jede ,Erscheinung-von'“ (Hu XXXIV, 179; C17). 
Tal y como son captados en la reflexión ni los actos ni las unidades hiléticas pertenecen a la corriente de vida (Lebensstrom) que efectúa la prototemporalización, sino a la esfera inmanente. Antes de esta hay un movimiento previo pasivo del flujo en el que son vividos como unidades los actos y los datos hiléticos. Se trata de una "conciencia-de" en el sentido de las retenciones y las protenciones que forman parte de este flujo pasivo. Esta pre-intencionalidad no es algo que le corresponda a un cierto plano de la conciencia anterior al flujo que es captado inmanentemente si se reflexiona sobre él, sino que se trata del movimiento pasivo que es la corriente misma.

A través de una reflexión nos podemos dirigir a un "datum" (entre comillas porque se trata de un dato hilético o de un acto), a una vivencia de mi flujo de conciencia, y a través de este dirigirse al "datum", podemos pasar a dirigirnos al acto en cuanto que algo vivo, al flujo mismo, a la pre-temporalización fluyente en la que se constituye la vivencia misma. El movimiento temporalizador de la corriente, la vida pretemporalizadora, se descubre regresivamente en la reflexión como una vida que ocurre en un pre-tiempo. Según Husserl, esta fenomenología que habría descubierto la doble articulación del plano inmanente, el hecho de que hay un movimiento pre-temporalizador y unas unidades inmanentes temporalizadas, es una fenomenología muy desarrollada, una fenomenología que ha ido realmente lejos. El descubrimiento de que la vida absoluta trascendental de la conciencia consiste en una pre-temporalización, en la constitución viva de un pre-tiempo, en este movimiento vivo de constitución, es lo último a lo que llega la fenomenología.

En el año 1932 Husserl realiza una serie de cambios a los pliegos anteriores con la intención de dejar bien claro que la pre-temporalización del flujo no constituye tiempo, sino que es el sujeto que reflexiona el que "introduce" (einfliesst) la temporalidad en el flujo de conciencia. La verdadera temporalización es la que efectúa el yo fenomenologizante-trascendental. Es el yo que reflexiona el que introduce la temporalización en el flujo primario: no hay una "temporalización" previa sino que es la reflexión del yo la que hace temporal el mero flujo de datos. La temporalización del flujo inmanente es el resultado de una actividad reflexiva del yo sobre su propia "vida fluyente"; toda temporalización es el resultado de un trabajo o disposición del yo. La intencionalidad pasiva, la intencionalidad del flujo de conciencia no puede seguir siendo considerada en sentido propio "intencionalidad":

Tras las aclaraciones más tardías (1932) he llegado al convencimiento de que en sentido propio no hay dos tipos de intencionalidad, y, por ello, ninguna pre-temporalización en sentido propio. La verdadera temporalización, que es efectuada y presupuesta en la dación temporal evidente de la corriente de vivencias, es la del yo trascendental-fenomenologizante. Gracias a que el yo la efectúa originariamente se produce con la evidencia de la temporalidad de la 
vivencia, y así es esto una verdad apodíctica. La temporalidad es entonces de esta forma una disposición del yo, originaria o adquirida (Hu XXXIV, 181; C $17,65 b){ }^{1}$

Lo que sería necesario explicar es cómo es posible efectuar una reflexión temporalizadora sobre un mero flujo de datos anterior a la temporalización. Tal y como se decía en los manuscritos de Bernau no es posible ejercer ningún tipo de captación activa de un mero flujo de datos: el yo sólo puede captar unidades previamente formadas. Para justificar la posibilidad de la reflexión sobre el flujo de datos inmanentes Husserl habla ahora de un cierto pre-ser que no puede ser el resultado de una constitución intencional. De ser así, la constitución intencional necesitaría de una constitución intencional de un nivel superior que constituiría su propia unidad, y esta a su vez de otra, y así sucesivamente. "Se observa que si el fluir continuo tuviese por sí mismo en cuanto corriente ya intencionalidad real, caeríamos en un regreso al infinito" (Hu XXXIV, 181; C17, 65b). ${ }^{2}$ La solución es negar la existencia de cualquier tipo de intencionalidad real en el flujo pasivo de conciencia y suponer que en éste se encuentra de algún modo "operante" algún tipo de preintencionalidad que configura una serie de unidades (el "datum") sin temporalizarlas. Tal y como se defendía en algunos pasajes de los manuscritos de Bernau Husserl afirma aquí que todo aquello que puede ser tema de reflexión para el yo es algo ya constituido previamente, algo que es un ente para el yo, algo sobre lo que el yo puede dirigir su mirada en un acto perteneciente a la vida despierta (Wachleben). Normalmente la protocorriente de conciencia transcurre sin ser objeto temático de ningún acto reflexivo. Sin embargo, el fenomenólogo la tematiza reflexionando sobre ella y genera a partir de este campo de lo pre-óntico lo óntico. En la reflexión se lleva a cumplimiento aquella pre-constitución marcada o indicada por la pre-intencionalidad del flujo originario de conciencia. El fenomenólogo transforma el pre-ser de la corriente originaria en un objeto inmanente; capta la subjetividad transcendental que él es (y que los otros son) solamente según su ser objeto posible de experiencia: es decir, no capta el pre-ser de esta subjetividad trascendental tal y como este es pre-siendo, sino que lo capta a través de

1 „Nach den späteren Klärungen (1932) bin ich zur Überzeugung gekommen, dass es nicht zweierlei Intentionalität im eigentlichen Sinn gibt und somit in eigentlichen Sinn keine Vor-Zeitigung. Die wirkliche Zeitigung, die in der evidenten zeitlichen Gegebenheit des Stromes der Erlebnisse vorausgesetzt und getätigt ist, ist die des transzendentalphänomenologisierenden Ich. Indem es sie ursprünglich tätigt, hat es die Evidenz der Erlebniszeitlichkeit und so ist das apodiktische Wahrheit. Zeitlichkeit ist eben in jeder Weise Ichleistung, ursprüngliche oder erworbene" (Hu XXXIV, 181; C 17, 65b).

2 „Man sieht ja, daß, wenn das ständige Strömen in sich als Strom immer schon wirkliche Intentionalităt hätte, wir auf einen unendlichen Regreß kämen“ (Hu XXXIV, 181; C17, 65b). 
una transformación de este pre-ser del flujo originario en algo óntico. El fenomenólogo sólo puede captar aquello de la subjetividad transcendental que se ofrece a la experiencia, de forma que el movimiento mismo de constitución que es la subjetividad transcendental le permanece oculto. La investigación de la estructura de la subjetividad trascendental antes de ser captada, en su pre-ser mismo, no puede ser llevada a cabo si se quieren respetar los límites de la fenomenología.

Es por ello por lo que Husserl termina afirmando que el fenomenólogo realiza apercepciones trascendentales: a partir de la aprehensión aperceptiva realizada sobre el flujo originario de conciencia y sobre el proto-yo capta una corriente inmanente de vivencias y un yo transcedental-inmanente correlato de ésta. Pero al mismo tiempo, el hecho de que de una aprehensión del fenomenólogo surja un yo transcendental implica que tiene que haber algo en el flujo originario que le corresponde al yo bajo la forma de un yo pre-siendo. Por ello es por lo que se puede afirmar que también tiene que haber cierto proto-yo predonado continuamente operante y previo a la reflexión. La cuestión entonces no es que no exista ningún tipo de pretemporalización, sino que no podemos ir más allá de la temporalización, no podemos salirnos de aquello que se nos da en la reflexión: no podemos ir más allá del flujo temporalizado, del flujo como ser. No podemos saber nada acerca de aquello que lo precede, no podemos ni siquiera hablar de un hipotético no-ser, no tenemos ninguna dación de ello. Es por ello por lo que Husserl tiende paulatinamente a desatender el discurso acerca de una pre-temporalización previa a la entrada en juego del yo fenomenológico. Al final del suplemento XIII (Hu XXXIV, 184) aparece un añadido del año 1932 en el que vuelve a insistir en que es cuando el yo trascendental-fenomenologizante reflexiona y tematiza la vida fluyente-permaneciente de conciencia cuando se efectúa una temporalización en sentido propio. Normalmente, las transformaciones retencionales son meramente vividas. La reflexión consiste en un proceso en el que se capta algo que ha transcurrido: la reflexión recorre una peculiar modificación retencional en la que no se trata de que se vivan simplemente las transformaciones del flujo, sino de que aquello que es objeto de la retención se convierte en un objeto que gana una posición temporal concreta, que se muestra a la reflexión como siendo en un punto temporal concreto. La reflexión es un captar y un retener dentro de la modificación retencional que me permiten convertir aquello captado en algo situado en un punto temporal concreto, que me permiten temporalizarlo.

La solución de esta dificultad consiste claramente en que yo, el yo trascendental fenomenologizante, al tematizar la vida fluyente permaneciente realizo una temporalización propia, identificadora, en la medida en que no sólo vivo la modificación retencional, sino que realizo en ella un captar, un conservar en sentido egoico y a partir de aquí realizo la apercepción en cuanto algo que es, 
algo identificable repetible. Objetivando mediante una actividad reflexiva posterior veo y digo: a la esencia de la corriente de vivencia, que por sí misma no realiza ninguna temporalización y que no es ninguna operación de conciencịa a ella correspondiente, le pertenece de forma continua la posibilidad de insuflarle, por así decir, intencionalidad. Pero la verdadera temporalización no es la de la corriente en cuanto corriente, sino la mía, la del yo trascendental fenomenológico (Hu XXXIV, 184; C 17, 64b). ${ }^{1}$

\section{Algunos apuntes finales en relación a los manuscritos $\mathrm{C}$.}

Antes que una serie de conclusiones, señalo aquí ciertas cuestiones abiertas que la crítica especializada apunta y que considero relevantes. La primera de ellas se refiere al reconocimiento último por parte de la fenomenología de Husserl de la existencia de una facticidad insuperable. Se trata de un movimiento absoluto que Husserl denomina "arracional", el "sistema del ser absoluto arracional" ( $\mathrm{Hu} \mathrm{XV,} \mathrm{669),} \mathrm{en} \mathrm{el} \mathrm{sentido} \mathrm{de} \mathrm{que} \mathrm{se} \mathrm{trata} \mathrm{de} \mathrm{un}$ primer movimiento previo a la razón, una facticidad que simplemente puede ser constatada. El presente viviente es una cierta "facticidad" absoluta primera, un "hecho" que no es nada hecho, sino un movimiento previo anterior a la temporalización particular de cada una de las mónadas, una fuente genética primera que otorga ser y sentido. La facticidad consiste en el hecho de que hay conciencia y de que esta conciencia opera de una determinada forma, por lo que preguntar por los motivos de esta facticidad no es posible. Hay un hecho primordial consistente en un flujo de la conciencia que fluye y acerca del cual no tiene sentido hacerse más preguntas. La facticidad del fluir es meramente "experienciable", "vivible", ni siquiera "experienciable como algo".

'Faktum' absoluto - la palabra Faktum está usada en un sentido contrario al suyo propio, así mismo ,hecho', aquí no hay un hacedor. Se trata de lo absoluto, que no puede ser tampoco caracterizado como ,necesario', que subyace a

1 „Die Lösung dieser Schwierigkeit besteht wohl darin, dass Ich, das phänomenologisierende transzendentale Ich, das strömende ständige Leben thematisierend, eben damit aktiv eine eigentliche Verzeitigung vollziehe, identifizierend, indem ich die retentionale Wandlung nicht nur erlebe, sondern in ihr Erfassen, Behalten in ichlichen Sinn übe und von da aus die Apperzeption als Seiendes, wiederholbar Identifizierbares etc. vollziehe. In nachkommender reflexiver Aktivität wieder vergegenständlichend sehe ich und sage ich: Zum Wesen des Erlebnisstromes, der in sich keine eigentliche Zeitigung vollzieht und keine entsprechende Bewusstseinsleistung ist, gehört meine ständige Vermöglickeit, ihm Intentionalität sozusagen einzuflösen. Aber die wirkliche Zeitigung ist nun nicht die des Stromes als Stromes, sondern meine, des transzendental-phänomenologischen Ich" (Hu XXXIV, 184; C 17, 64b). 
todas las posibilidades, a todas las relatividades, a todas las determinabilidades, y es dador de su sentido y de su ser (Hu XV, 669). ${ }^{1}$

Landgrebe afirma que el término "Faktum" se refiere tanto al concepto de existencia (como opuesto a esencia) como al concepto de hecho (como opuesto a "principio" Prinzip, en el sentido de que de él no se puede deducir nada, punto último o condición última para toda función y operación (Landgrebe, 1976, 37).

En segundo lugar, y como ya se ha apuntado, la duplicidad del concepto de yo resulta especialmente problemática. Existe una ambigüedad no resuelta, puesto que la relación entre el yo supratemporal (proto-yo) y el yo inmanente objeto de acciones y afecciones no recibe una explicación satisfactoria. Algo semejante objeta Derrida a lo largo de La voz y el fenómeno cuando asegura que el concepto de vida es empleado injustificadamente para referirse tanto a la vida de la conciencia trascendental y a la vida de la conciencia empírica. La vida trascendental exigiría quizás otro término que el de vida, si se atiende al hecho de que una vez efectuada la reducción trascendental no debería ser equiparada con ninguna vida empírica ${ }^{2}$. Ya en el manuscrito $\mathrm{C} 3$ el propio Husserl declaraba ser consciente de la dificultad que supone explicar como desde el presente viviente del proto-yo se deslinda o surge un yo correlato de afecciones y acciones. ${ }^{3}$

Bernet afirma que Husserl defiende la existencia de una subjetividad situada más allá de la temporalidad del flujo de la conciencia, la idea de la identidad desnuda de un yo puro (Bernet 1994, 212). Lo cierto es que no se trata de que esté situada más allá, sino de que esta subjetividad es la propia temporalidad de la conciencia. En cuanto nunc-stans el presente viviente coincide con el yo como polo puro; en cuanto nunc-fluens con el yo como ejecución, constitución, donación.

1 “Absolutes 'Faktum' - das Wort Faktum ist seinem Sinn nach verkehrt hier angewendet, ebenso ,Tatsache', hier ist kein Täter. Es ist eben das Absolute, das auch nicht als "notwendig" bezeichnet werden kann, dass allen Möglichkeiten, allen Relatitivitäten, allen Bedingtheiten zugrunde liegt, ihnen Sinn und Sein gebend ist" (Hu XV, 669).

2 "Si se concluye según un gesto muy husserliano en su estilo que los conceptos de vida empírica (o en general mundano) y de vida trascendental son radicalmente heterogéneos y que los dos nombres mantienen entre ellos una relación puramente indicativa o metafórica, entonces la posibilidad de esta relación es la que carga con todo el peso de la cuestión" (Derrida 1967, 9).

3 "Me encuentro con la cuestión acerca de cómo se produce en el presente viviente la separación de un yo específico que es unidad de afecciones y acciones específicamente egoicas. ¡La cuestión queda aquí detenida en su mero inicio!" (C3, 49a) "Ich stehe jetzt vor der Frage, wie sich in der lebendigen Gegenwart die Abscheidung eines spezifischen Ich als Einheit spezifisch ichlicher Affektionen und Aktionen vollzieht. Die Frage bleibt stehen mit dem bloßen Eingang! (C3, 49a). 
Tanto en Ideas II como a lo largo del volumen $\mathrm{Hu} \mathrm{XI}$ dedicado a la síntesis pasiva Husserl insiste en numerosas ocasiones en el hecho de que el cuerpo es el elemento a través del que se conoce y a través del que nos comunicamos con el mundo. Las posibilidades del cuerpo, el "yo puedo", podrían ser consideradas el verdadero núcleo de las constituciones. Ya en el parágrafo $\S 3$ se hablaba del cuerpo orgánico (Leib) como la pieza clave de los fenómenos perceptivos: sería el centro de un sistema subjetivo que incluiría las posibilidades que el "yo puedo" puede efectuar libremente (dirigirme a este o a este otro punto). En otras ocasiones se habla del cuerpo orgánico como punto cero de la orientación espacial, centro (Hu XI, 297). De acuerdo con esta idea las protenciones también podrían ser entendidas como las posibles cinestesias que se pueden realizar. De hecho, en una nota a pié de página afirma que la 'esfera de presente hilética' originaria es transformada a través de diferentes cinestesias, es decir, las protenciones premarcarían el conjunto de las posibles cinestesias que el cuerpo puede realizar, o visto al revés: las posibles cinestesias delimitarían el estilo de las protenciones (Hu XI, 428). Esta perspectiva, que permitiría comprender la temporalidad a través del cuerpo, no recibe sin embargo mayor desarrollo por parte de Husserl. Este último camino, que en líneas generales sería el propuesto por Merleau-Ponty, propondría que el proto-yo sale al mundo en virtud de su estar encarnado en un cuerpo.

Klaus Held se interroga acerca de los motivos por los que el presente viviente constituye un flujo inmanente y sale de su interioridad absoluta. Según él la solución no la puede aportar una fenomenología reflexiva-descriptiva. Held objeta que todavía habría que aclarar primero trascendentalmente cómo el yo trascendental se coloca en este cuerpo. Lo cierto es que la cuestión que plantea Held tendría sentido si en algún momento se hubiese planteado la posibilidad de que el proto-yo permaneciese cerrado en sí al modo de alguna unidad circular. Sin embargo, a nuestro entender Husserl lo concibe como un yo que opera, dona sentido, de forma tal que está constantemente ya saliendo de sí: si bien permanece él mismo "escondido" no cesa de constituir sentido. Esta es ciertamente la única apertura posible: no puede mostrarse en sí mismo, como yo operante, en un mundo de sentidos, sino que lo que tiene que hacer es precisamente operar. Creemos que el planteamiento de Held da pié a una deriva metafísica que la filosofía de Husserl pretende en todo momento evitar. Held afirma:

Que a la identidad supuestamente muerta y rígida del yo le subyace un distinguirse de sí mismo vivo, había sido reconocido y formulado mucho antes de Husserl por el idealismo alemán, sin que áquel por supuesto lo supiese, con una fuerza sin par, por ejemplo, en la doctrina de Fichte de la ,Tathandlung' o en la presentación de Hegel de la autoconciencia y su vida en el fragmento , $\mathrm{La}$ 
verdad de la certeza de sí mismo' en la ,Fenomenología del espíritu' (Held 1966, 170).

A nuestro entender, la 'autoconciencia' husserliana no es ningún tipo de autoconciencia, sino un conciencia refleja previa, al contrario que la acción-hecho fichteana. Además, una intuición intelectual al estilo de la fichteana no tiene en cuenta su propio carácter temporal. El tiempo que transcurre entre el acto reflexivo y su objeto no es un problema para Fichte $(1997, \S 1)$. Mientras que para la tradición idealista la identidad del yo procede de un acto de autoconciencia, para Husserl la identidad del yo no resulta de un identificarse, sino de un ser protounitariamente. El yo es idéntico consigo mismo debido a que es uno consigo mismo en su presente viviente. La comparación que Held hace de Husserl con el idealismo alemán no nos parece justificada, puesto que el motivo conductor de la fenomenología no es ni mucho menos la autoposición del yo de sí mismo, sino la donación de los sentidos que forman mundo. Otro tema es que la fenomenología abra el espacio necesario para el desarrollo de este tipo de reflexiones situadas más allá de ella. Siguiendo en esta línea, mucho más arriesgado nos parece buscar el motivo de esta autoescisión del yo trascendental en razones teológicas o el paso que Held da desde cada proto-yo a la intersubjetividad en virtud de su anonimidad. 'Según Held, del hecho de que mi "yo opero" me es tan anónimo como el "yo opero" ajeno, puede deducirse que a cada subjetividad la precede algún tipo de estructura en la que todos los yos están unidos intersubjetivamente en virtud de su anonimidad. Esta comunidad anónima de las mónadas vendría en definitiva a ser una manifestación de Dios, en la medida en que en ambos casos se trataría de un esconderse al pensamiento para mantenerse en un desconocimiento insuperable. El proceso de reflexión fenomenológica podría ser equiparado a cierta interiorización religiosa en la que se establece a través de una previa comunidad con Dios una comunidad con los otros y con el mundo:

El carácter de oculto esencial de Dios para el pensamiento yace en la dirección del desconocimiento insuperable que tiene ya para mí mi propio nun stanc anónimo y fáctico (Held 1966, 181). ${ }^{2}$

El problema es que pese a su anonimidad el presente viviente no puede dejar de ser tan a la ligera mi propio presente viviente. La presencia de mi presente viviente se me dará siempre con un grado de evidencia diferente a

1 "Dios puede quizás ser pensado como la razón egoica de la autocomunalización" (Held 1966, 181).

2 "Die wesenhafte Verborgenheit Gottes für das Denken liegt in der Richtung der unaufhebbaren Unbekanntheit, die schon mein eigenes anonymes und faktisches nun stanc für mich hat" (Held 1966, 181). 
aquel con el que el que se me da la esfera de presencia viviente de otro. Esta, tal y como se explica en la quinta Meditación cartesiana (Hu I), no me es accesible más que a través de cierta apercepción (no deductiva) y no a través de la misma reflexión originaria mediante la que "capto" mi presente viviente.

Sin caer en los excesos de Held, también Serrano de Haro apunta en su excelente tesis doctoral de forma mucho más comedida hacia la metafísica como una posibilidad de una profundización de cierta vertiente teólogica abierta en la fenomenología. En su caso se trata de la posibilidad de concebir una necesidad absoluta con que la cada fase pertenece al transcurso de la conciencia, suponemos que viendo en esto una posible manifestación de la necesidad divina:

Pues tiendo a creer que la comprensión de la conciencia subyacente como corriente de conciencia absoluta apunta con fuerza a la idea de que ni una sola fase de actualidad subjetiva puede tratarse como contingente. / Seguramente esta reflexión rebasa el ámbito en que la investigación fenomenológica persigue las condiciones de la concreción para entrar de lleno en el ámbito metafísico [...] (Serrano de Haro 1990, 588/9).

Buena prueba de que en este punto se desbordan los límites de la fenomenología la ofrece el hecho de que en este mismo terreno Brand termina afirmando totalmente lo contario, es decir, que hablar de una temporalidad del yo es lo mismo que hablar de su libertad, en relación a aquel terreno futuro de posibilidad todavía abierto que está continuamente trascendiendo la facticidad de su pasado. ${ }^{1}$ El propio Husserl afirma en Filosofia primera que el estudio de las razones acerca de por qué lo fáctico está estructurado de la forma que lo está viene a continuación de la fenomenología y entra dentro del ámbito de problemas estudiados por la metafísica: "La facticidad es el campo no de la fenomenología o de la lógica, sino de la metafísica" (Hu VII, 394). ${ }^{2}$

1 "Nachdem wir mit Husserl immer mehr das Ur-sein des Ich als Zeitlich-sein in den Griff bekommen, müssen wir mit ihm sagen, die Zeitlichkeit als Ur-Form des Ich, als Ichlichkeit des Ich, ist seine Freiheit. Freiheit ist das offenbleibende und sich ständig übersteigende Bestimmtsein des Ich. Dies weist sich aus in der Vergangenheit und in der Zukunft, in Gewordenheit und Zukünftigkeit, dabei immer in eins, d.h. in vor- und rückwirkender Synthesis" (Brand 1955, 127).

2 "Die Faktizität ist das Feld nicht der Phänomenologie und Logik, sondern der Metaphysik" (Hu VII, 394). 


\title{
BIBLIOGRAFÍA:
}

BEILS, K. B., Transzendenz und Zeitbewusstsein. Zur Grenzproblematik des transzendental-phänomenologischen Idealismus, Bouvier, Bonn, 1987.

BERNET, R.:

- La vie du sujet, P.U.F., Paris, 1994.

- Conscience et existence phénoménologiques, P.U.F., 2004.

BRAND, G., Welt, Ich und Zeit. Nach unveröffentlichten Manuskripten Edmund Husserls, La Haya, Martinus Nijhoff, 1955.

DEPRAZ, N., "Temporalité et affection dans les manuscrits tardifs sur la temporalité (1929-1935) de Husserl”, Alter 2 (1994), 63-85.

DERRIDA, J., La voix et le phénomène. Introduction au problème du signe dans la phénoménologie de Husserl, Quadrige/PUF, Paris, 1967.

EIGLER, G., Metaphysische Voraussetzungen in Husserls Zeitanalysen (Monographien zur philosophischen Forschung 24), A. Hain, Meisenheim/Glan, 1961. HELD, K., Lebendige Gegenwart, Martinus Nijhoff, Den Haag, 1966.

FICHTE, Grundlage der Wissenschaftslehre (1794), ed. Meiner, Hamburgo, 1994. MONTAVONT, A., De la passivité dans la phénoménologie de Husserl, PUF, Paris, 1999.

SERRANO DE HARO, A., Fenomenología y ontología trascendental, Universidad Complutense de Madrid, tesis doctoral, 1990.

\begin{abstract}
In this article the author presents Husserl's analysis of the problem of time-consciousness in the C-Manuscripts (1929-1934). He tries to discuss the reasons why Husserl introduces the concept of "living present" and the necessity of distinguishing the originary temporalizing flux of absolute consciousness and the immanent time where acts are placed when they become object of an act of reflection. Another important issue is the introduction of a Ur-Ich, which works anonymously and temporalizes itself. It will be also studied why Husserl considers at the end that temporalization is an non-intentional passive process that works at the deepest level of consciousness.
\end{abstract}

